A N N A L E S Annales de Bretagne et des Pays de l'Ouest

Anjou. Maine. Poitou-Charente. Touraine

113-2 | 2006

Varia

\title{
Les maires du Morbihan (1929-1959)
}

\section{Christophe Rivière}

\section{OpenEdition}

\section{Journals}

Édition électronique

URL : http://journals.openedition.org/abpo/841

DOI : 10.4000/abpo.841

ISBN : 978-2-7535-1502-4

ISSN : 2108-6443

Éditeur

Presses universitaires de Rennes

Édition imprimée

Date de publication : 30 juin 2006

Pagination : 135-184

ISBN : 978-2-7535-0331-1

ISSN : 0399-0826

Référence électronique

Christophe Rivière, «Les maires du Morbihan (1929-1959) », Annales de Bretagne et des Pays de l'Ouest [En ligne], 113-2 | 2006, mis en ligne le 30 juin 2008, consulté le 01 mai 2019. URL : http:// journals.openedition.org/abpo/841; DOI : 10.4000/abpo.841 


\title{
Les maires du Morbihan (1929-1959)
}

\author{
Christophe RIVIERE \\ Professeur d'histoire et de géographie, lycée Guy-de-Maupassant (Fécamp) \\ Doctorant, université de Bretagne Occidentale (Brest)
}

En 1913, André Siegfried, dans un ouvrage pionnier, présentait la région vannetaise comme un pays de structure féodale où dominait le vote en faveur de la noblesse. Il insistait cependant sur les mouvements de fond qui agissaient sur les comportements politiques des électeurs ${ }^{1}$. Ces processus politiques repérés au début du $\mathrm{Xx}^{\mathrm{e}}$ siècle et qui participent du mouvement de républicanisation de la France de l'Ouest, sont toujours à l'œuvre, au niveau local, dans le Morbihan, dans les dernières décennies de la Troisième République. D’autres phénomènes politiques, plus marqués par la conjoncture, peuvent aussi infléchir le visage de la " démocratie au village ". C'est cette articulation entre le contexte national et le contexte local qui nous intéresse ici. Autrement dit, quelles ruptures les dynamiques nationales ont-elles engendrées chez les maires morbihannais entre 1929 et 1959? Au milieu des années 1930, le contexte général est marqué par la montée en force du Front populaire. Puis à partir de 1940, ce sont les ruptures consécutives à la Seconde Guerre mondiale, à la mise en place du Régime de Vichy, puis à la Libération et aux remous de cette période, qui perdurent au moins jusqu'en 1953 dans le Morbihan, qui marquent de leur empreinte la vie politique municipale. À partir des élections de 1953, les ondes de choc de la guerre s'atténuant, on assiste à une stabilisation du corpus qui retrouve un aspect proche de celui de la fin des années $1930^{2}$.

1. SiEGFRIED, André, Tableau politique de la France de l'Ouest, Paris, Armand Colin, 1913, réédition de l'Imprimerie nationale, 1995, notamment les pages 217 sqq.

2. Ces problématiques ont déjà été abordées au niveau régional dans le cadre d'une enquête de l'IHTP (Institut d'histoire du temps présent); pour une approche synthétique on consultera Jacqueline SAINCLIVIER, " Culture politique et pouvoirs locaux en Bretagne (1935-1953) ", Annales de Bretagne et des pays de l'Ouest, tome 103, n 3, 1996, p. 11-30. 


\section{Les maires du Morbihan et les enjeux nationaux dans les années 1930}

Au cours des années 1930, la physionomie politique et le corpus des maires du département restent stables. Les taux de renouvellement des maires sont de $18 \%$ en 1929 et de $26,44 \%$ en $1935^{3}$. Les grands enjeux politiques nationaux ont des répercussions dans le département mais leurs impacts sont très atténués lorsque l'on observe les résultats des élections municipales. Néanmoins, des mouvements qui s'inscrivent sur le temps long sont repérables. La droite monarchiste voit ses positions s'effriter progressivement, et la gauche progresse à chaque scrutin.

\section{Une droite en voie de républicanisation}

La lecture des cartes 1 et 2 qui présentent l'étiquette politique des maires du Morbihan après les élections municipales de 1929 et de 1935, corrobore l'image d'un département très ancré à droite. La géographie politique de l'entre-deux-guerres confirme l'existence d'un " bloc conservateur $^{4}$ " morbihannais, localisé à l'est du département et composé des maires conservateurs et des maires ralliant la bannière des républicains de l'Union républicaine démocratique (URD). Au niveau local, la différence est souvent ténue entre ces deux étiquettes, qui manifestent la même fidélité au catholicisme, le même souci de défendre la paysannerie, mais qui divergent dans leur position vis-à-vis du régime républicain.

Une part importante des conservateurs morbihannais adhère au traditionalisme politique qui rêve du retour d'une monarchie en France ${ }^{5}$. Le rejet de la République et de ses symboles perdure longtemps dans ces campagnes orientales du département. En juillet 1939, par exemple, le maire de Saint-Jacut-les-Pins, dans l'arrondissement de Vannes, Timothée Jourdain de Coutance, refuse de commémorer le 14 juillet et interdit de faire flotter les 3 couleurs sur la mairie ${ }^{6}$. Ce courant conservateur concerne essentiellement des maires ruraux qui appartiennent majoritairement à la noblesse. Ainsi, 61,5\% des maires conservateurs de l'arrondissement de

3. On retrouve les mêmes constantes dans les arrondissements étudiés lors de l'enquête coordonnée par AgulHon Maurice, GiRARd Louis, RoBerT, Jean-Louis, SERMAn, William (dir.), Les Maires en France du Consulat à nos jours, Paris, Publications de la Sorbonne, 1986, notamment les tableaux présentant la durée moyenne de l'exercice des fonctions de maire p. 71 et 72 .

4. L'expression est de Jean-Jacques MONNIER, Le Comportement politique des Bretons, Rennes, PUR, 1994, p. 45.

5 . Pour de plus amples informations sur ce courant on se reportera à la synthèse de Jacques Prevotat, " La culture politique traditionaliste ", dans BERSTEIn, Serge (dir.), Les Cultures politiques en France, Paris, Le Seuil, 1999, p. 33-67. En ce qui concerne le Morbihan on consultera la biographie de Francis de Petiville, Gustave de Lamarzelle, un homme, un combat, Paris, SICRE, 2000. Ce dernier, député puis sénateur du Morbihan de 1884 à 1924, est l'une des dernières grandes figures du mouvement royaliste du département.

6. Information extraite d'un article du journal Le Populaire, daté du 17 juillet 1939. 
Carte 1 - Élections municipales de 1929 : étiquettes politiques des maires du Morbihan

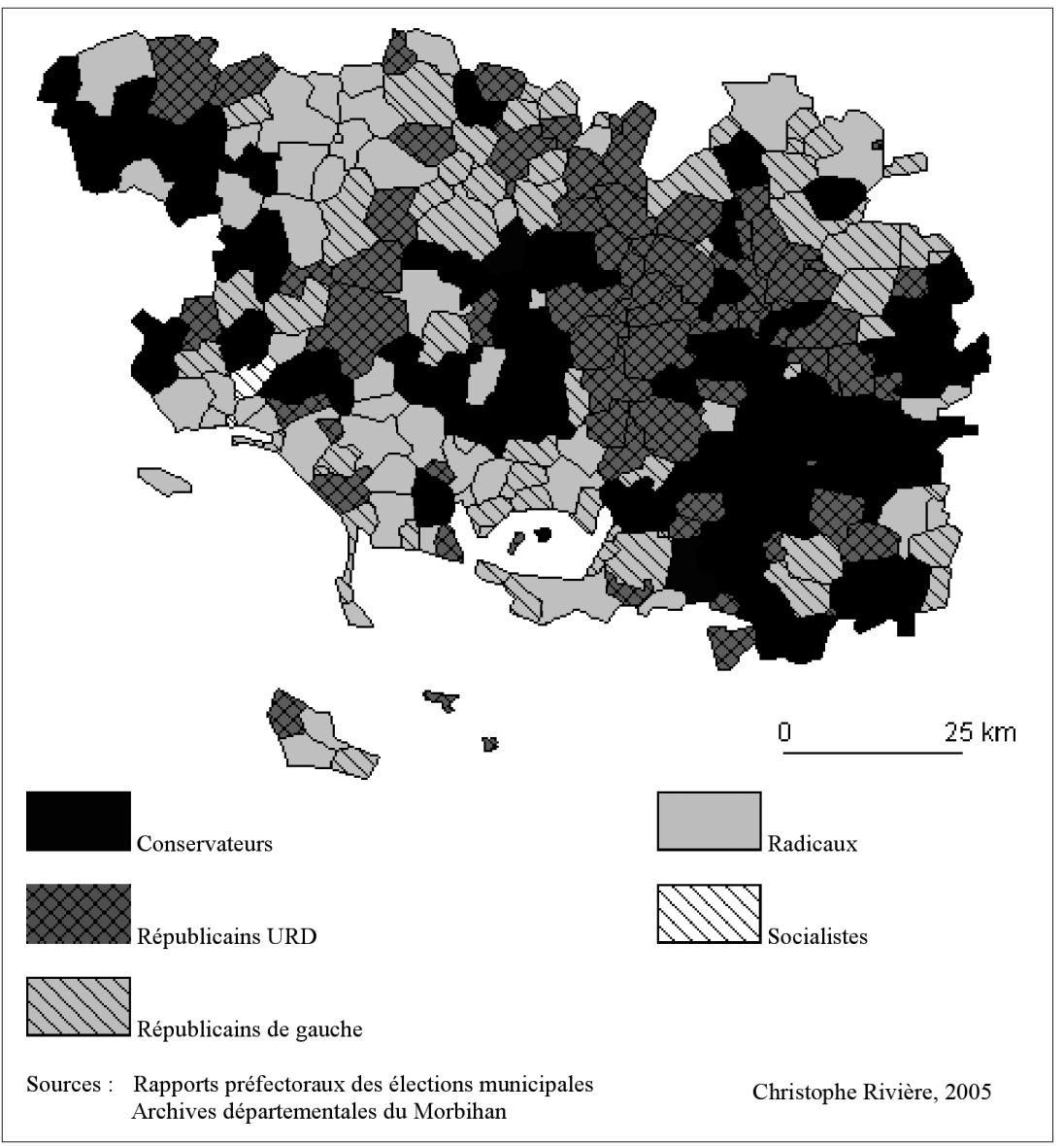

Vannes sont nobles ${ }^{7}$. Au sein de ce courant conservateur on peut distinguer trois figures de notables.

Tout d'abord, le noble issu de la famille qui administre traditionnellement la commune. Ce type d'élu est souvent monarchiste. À titre d'exemple, nous pouvons citer la famille du Halgouët de Poulpiquet qui domine la commune de Guégon et le canton de Josselin. Hervé du Halgouët est élu conseiller général du canton de Josselin en 1919. En 1943, il est nommé conseiller départemental, puis vice-président de cette instance. Cet élu est également un historien reconnu, il préside la Société polymathique du Morbihan et il est

7. Pour le recensement de ces maires nobles nous nous sommes arrêtés à la présence de la particule. 
Carte 2 - Élections municipales de 1935 : étiquettes politiques des maires du Morbihan

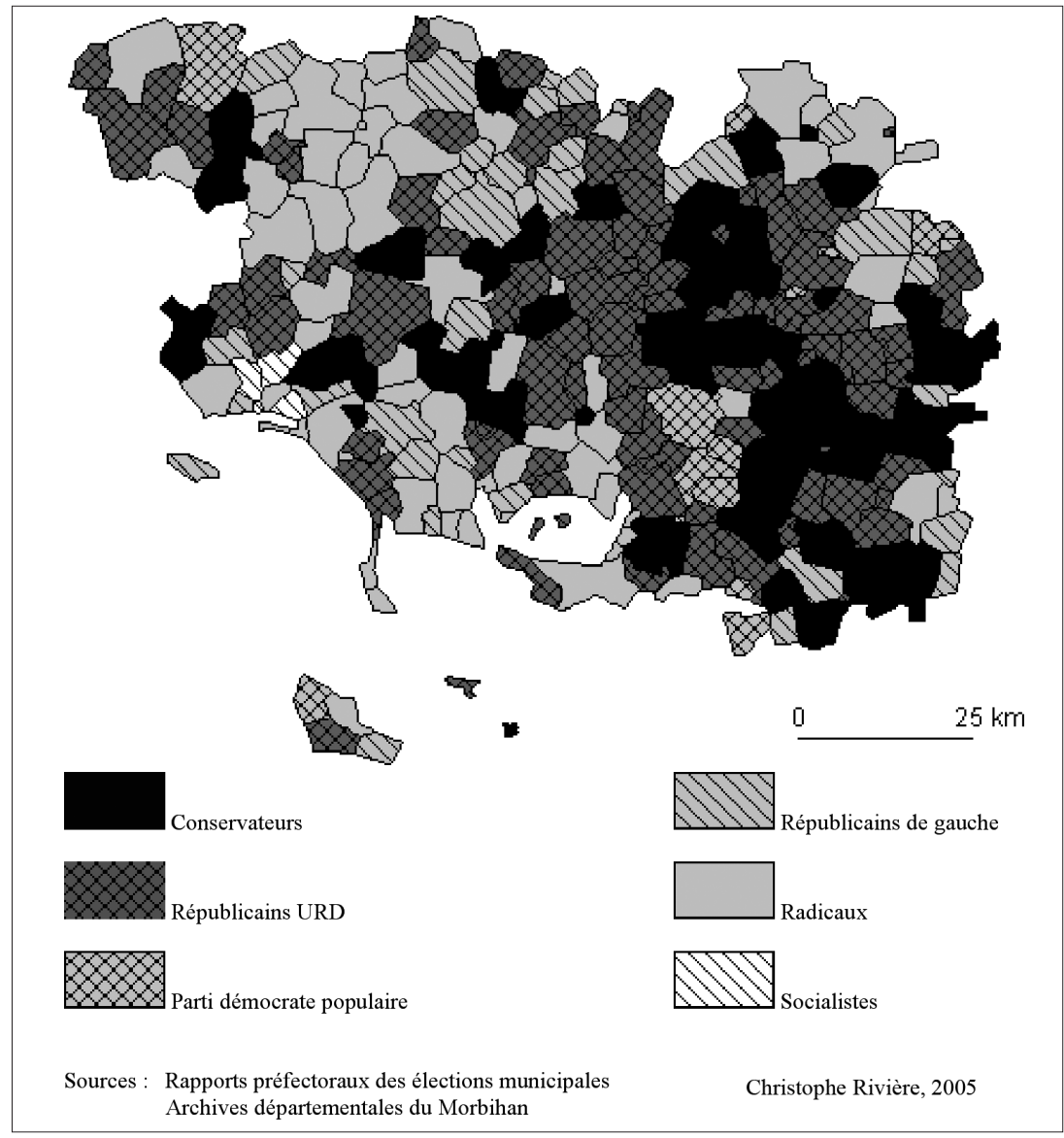

également vice-président de la Société d'histoire et d'archéologie de Bretagne. En 1944, le Comité départemental de libération (CDL) du Morbihan le révoque de son mandat de conseiller général; son fils, Yves du Halgouët est élu à sa place. Après plusieurs tentatives infructueuses, il prend la tête de la mairie de Guégon en 1959 sous la bannière du Centre national des indépendants (CNI). Yves du Halgouët conserve le canton jusqu'en 1982, date à laquelle il cède la place au duc Josselin de Rohan, et la mairie jusqu'en 1985. Cette famille reste à la tête de la commune pendant 26 ans et à la tête du canton durant 53 années. Il faut également souligner qu'une branche de la même famille contrôle la commune de Saint-Just en Ille-et-Vilaine ${ }^{8}$.

8. Renseignement extrait de Jean-Jacques Monnier, Le Comportement politique des Bretons, op. cit., p. 281. On pourra également compléter par sa notice biographique dans 
Le deuxième type de notable conservateur regroupe des élus qui n'appartiennent pas à la noblesse mais qui dominent socialement leur village. Leur adhésion à la doctrine conservatrice n'englobe pas forcément la doctrine monarchiste mais ils sont conservateurs car ils sont catholiques militants, attachés à une organisation séculaire et immuable des campagnes, et participent à l'encadrement des masses paysannes par le biais des syndicats agricoles. On les retrouve en effet dans les structures de l'Union des syndicats agricoles de la Bretagne méridionale (USABM), affiliée à l'Union centrale des syndicats agricoles. Ils partagent d'ailleurs souvent les places de direction avec les conservateurs issus de la noblesse. Louis Le Léannec, maire de la commune de Caudan dans l'arrondissement de Lorient, incarne ce profil d'homme politique. Il est réélu maire de 1925 à 1965, est nommé conseiller départemental et conseiller national en 1943, puis élu sénateur de 1948 à 1959. En 1929 et 1935, il est élu sous l'étiquette de conservateur ${ }^{9}$. Ce notable domine politiquement et socialement sa commune de Caudan. Il est d'ailleurs domicilié au château de Manéglio, symbole de sa position sociale. Parallèlement à sa carrière politique, il entame une carrière syndicale dans la mouvance agricole conservatrice de la Bretagne méridionale. Il préside l'Union des syndicats agricoles de la Bretagne méridionale. En 1928, ildirige la Caisse régionale de secours mutuels agricoles de la Bretagne méridionale et il est élu, par les associations et les groupements agricoles, président de la Chambre d'agriculture du Morbihan ${ }^{10}$.

Le dernier type de notable conservateur est représenté par des maires liés, souvent de façon économique, au noble dominant la commune qui la dirige ainsi par personne interposée. En 1936, une élection municipale partielle est organisée dans la commune de Saint-Avé en raison du décès du maire radical-socialiste. Le conservateur Jean Alban est porté à la tête du Conseil municipal. Une fiche confidentielle de renseignements est demandée par le préfet au conseiller général radical-socialiste de Vannes-est, le

le Dictionnaire des gaullistes sous la Quatrième République, ouvrage à paraître aux éditions Honoré Champion, réalisé sous la direction de Bernard LACHAISE et sous le patronage de la Fondation Charles de Gaulle.

9. Ce dernier, né le 3 mai 1889 à Caudan (Morbihan), propriétaire exploitant, en est maire conservateur jusqu'en 1935. Il est réélu en 1945 comme URD, comme RPF en 1947, puis comme indépendant de droite en 1953, et enfin sous l'étiquette CNI à partir de 1959. Il effectue ses mandats de sénateur tout d'abord comme RPF puis comme indépendant de droite (1948-1959).

10. Sur l'USABM on pourra consulter L'Histoire de la Bretagne et des pays celtiques, D'une guerre à l'autre... Bretagne 1914-1945, tome 5, ouvrage collectif, Morlaix, Skol Vreizh, 1994, notamment les pages 34-37. Mais aussi l'étude essentielle de Suzanne BERGER, Les Paysans contre la politique. L'organisation rurale en Bretagne, 1911-1974, Paris, Seuil, 1975. Elle étudie minutieusement l'Union des syndicats agricoles du Finistère et des Côtes-du-Nord, appelée Office central de Landerneau, dont les objectifs et les moyens sont très proches de ceux de l'USABM, d'ailleurs la Bretagne méridionale réassure ses caisses mutuelles incendies, bétail et accidents auprès de l'Office central. Nous citons cet élément d'après l'étude de Francis CORVAISIER, Les Abbés démocrates. Église et émancipation paysanne en Bretagne au début du XX siècle, Rennes, Apogée, 2003, p. 172. 
docteur Marquet; celui-ci qualifie le nouveau maire « d'homme lige de monsieur de Salins ${ }^{11}$ ", principal propriétaire de la commune et résidant au château de Beauregard, à la sortie du bourg. Dans cette catégorie, nous pouvons également placer les maires qui sont restés longtemps, au sein du Conseil municipal, dans l'ombre d'un maire conservateur. Le cas du maire de Pleucadeuc dans l'arrondissement de Vannes est tout à fait éclairant. Émile Loyer est élu conseiller municipal en 1925. La commune est alors administrée par Georges de Montfort, maire depuis 1913. Il décède en 1937, et c'est Georges de Chabannes, conseiller général et gros propriétaire terrien ${ }^{12}$, qui lui succède. En 1944, Georges de Chabannes est révoqué de ses mandats par le CDL pour avoir soutenu le régime de Vichy. C'est alors qu'Émile Loyer est élu maire de la commune. Il apparaît comme conservateur. C'est le dernier avec le maire de Plumelec dans l'arrondissement de Lorient à user de cette étiquette. Sans conteste, l'influence du maire révoqué doit encore se faire sentir, mais le poids des traditions au sein du Conseil municipal apparaît aussi dans ce cas bien pesant ${ }^{13}$. En 1947, il délaisse cette étiquette pour celle du RPF, mouvement qu'il abandonne en 1953 pour la droite modérée (républicain national en 1953, modéré en 1959).

Cette permanence d'un vote conservateur peut s'expliquer par la conjonction de deux facteurs. L'existence " d'une culture politique partagée $^{14}$ " par l'ensemble des électeurs, culture fondée sur une mémoire commune où les épisodes de la chouannerie, de la contre-révolution et des luttes contre la loi de séparation des Églises et de l'État en 1905, occupent une place importante. L'autre élément, qui favorise la domination de ces notables, réside dans leur entrisme, au sein des structures d'encadrement des populations rurales; ils sont aidés en cela par le clergé au moins jusque dans les années $1930^{15}$. Cet encadrement passe notamment par la mainmise sur les syndicats ruraux, les coopératives et les associations de charité par exemple, mais aussi par l'existence de hiérarchies, de clientèles et de pressions de toutes sortes ${ }^{16}$. La domination de certaines communes par

11. Rapport au préfet le 11 avril 1936, Arch. dép. du Morbihan M5223.

12. Un rapport de Monsieur d'Asseville adressé au préfet du Morbihan, indique qu'il possède près de 2500 hectares de forêts et qu'il fait " travailler les trois scieries du coin ", non daté, Arch. dép. du Morbihan M5222.

13. On peut également penser que cette étiquette est accordée par un fonctionnaire de la préfecture qui, manquant d'information sur les orientations politiques du nouveau maire, reprend celle qu'il affichait dans le précédant Conseil municipal.

14. On se reportera à ce sujet à la synthèse de Pierre LEVEQue, Histoire des forces politiques en France, 1880-1940, Paris, Armand Colin, 1994, p. 225 sqq.

15. À ce sujet on pourra consulter l'ouvrage d'Eric MENSION-RIGAU qui analyse l'œuvre des campagnes, dont le but est de faire reprendre conscience à la noblesse de la position qu'elle doit occuper au sein des sociétés rurales, ainsi que du rôle exemplaire qu'elle doit jouer dans l'élan de reconquête religieuse des masses paysannes, dans Le donjon et le clocher. Nobles et curés de campagne de 1850 à nos jours, Paris, Perrin, 2003.

16. Claude-Isabelle Brelot, dans son étude sur trois cantons de l'arrondissement de Dole dans le Jura, à la physionomie politique proche, insiste sur l'importance « d'un réseau de parentèle et d'alliance pratiquant émulation et entraide pour mettre en œuvre une culture de patronage locale ", cela au détriment de l'univers contre-révolutionnaire et 
des familles nobles révèle l'existence de ces éléments qui sont souvent difficiles à mettre à jour ${ }^{17}$. Ces grands propriétaires n'hésitent pas, dans le cas de scrutins qui s'annoncent serrés, à promettre des compensations en nature pour favoriser leur élection. En 1925, le maire de Monteneuf Henry du Bot, fait battre le pays par ses partisans qui annoncent " la révolution prochaine, la destruction de la religion ${ }^{18}$ ". Pour certains hameaux acquis au candidat républicain, les conservateurs accordent aux habitants le droit de se servir en bois de construction sur les propriétés du maire. Ces pratiques lui assurent de confortables réélections jusqu'à sa mort en 1941.

Cependant, au fil des élections, le courant conservateur perd de son importance dans le département (tableau 1); nombre de maires vieillissants démissionnent ou décèdent, et leurs successeurs, souvent des agriculteurs, revendiquent leur appartenance à la droite républicaine. Mais on remarque aussi que certains maires nobles abandonnent le courant conservateur pour se reclasser au sein de cette droite parlementaire. En outre, le clergé rural soutient moins les candidats de la noblesse et les nouvelles générations de curés de campagne qui arrivent à la fin des années 1930 se sentent plus proches des idées développées par les démocrates chrétiens que du projet à leurs yeux suranné des conservateurs.

Tableau 1 - Étiquettes politiques des maires du Morbihan, 1929-1959

\begin{tabular}{|l|c|c|c|c|c|c|}
\hline & 1929 & 1935 & 1945 & 1947 & 1953 & 1959 \\
\hline Conservateurs & 75 & 56 & 2 & - & - & - \\
Républicains URD & 72 & 88 & 93 & 17 & - & - \\
Paysans & - & - & - & - & 9 & - \\
Républicains indépendants/Indépendants & & & & & & \\
de droite/Républicains nationaux/Modérés & - & - & 6 & 41 & 124 & 146 \\
RPF/Républicains sociaux/UNR & - & - & - & 75 & 22 & 32 \\
PDP/MRP & - & 12 & 50 & 50 & 37 & 26 \\
Républicains de gauche & 61 & 38 & 24 & 11 & - & - \\
Radicaux & 51 & 63 & 60 & 28 & 29 & 26 \\
Divers gauche & - & - & 3 & 9 & 11 & 3 \\
Socialistes SFIO & 2 & 4 & 18 & 27 & 29 & 27 \\
Communistes & - & - & 5 & 4 & 2 & 4 \\
\hline Total & 261 & 261 & 261 & 262 & 263 & 264 \\
\hline
\end{tabular}

Aux élections municipales de 1935, l'Union républicaine démocratique devient la première force politique du département. Cette droite qui adhère pleinement à la République reste attachée à la défense du catholicisme en

catholique. Brelot, Claude-Isabelle, "Fonction municipale et noblesse sous la III République ", dans Dumons, Bruno et Pollet, Gilles (dir.), Élites et pouvoirs locaux. La France du Sud-Est sous la Troisième République, Lyon, PUL, 1999, p. 427-440, citation p. 435.

17. Les exemples ne manquent pas pour le Morbihan, qu'il s'agisse des familles de Gouyon de Coipel à Cournon et Foucher de Carheil à Glénac dans l'arrondissement de Vannes, de la famille du Halgouët de Poulpiquet à Guégon dans l'arrondissement de Pontivy, ou de la famille de Pluvié à Plouay dans l'arrondissement de Lorient.

18. Rapport de M. Maheux, instituteur public à Monteneuf au Préfet du Morbihan, le 4 mai 1925, Arch. dép. du Morbihan M4661. 
général et de l'école privée en particulier ${ }^{19}$. Elle se montre très combative envers les candidats de gauche, notamment lors des élections législatives de $1936^{20}$. Le mouvement semble être en expansion dans le Morbihan depuis les années 1905-1910. La progression de ce courant est constante jusqu'en 1945. Le tableau 1 montre qu'en 1929, 27,58 \% des maires se réclament de cette étiquette, ils sont $33,71 \%$ en 1935 et $35,63 \%$ en 1945 . Cette progression, comme le montrent les cartes 1,2 et 3 , se fait principalement au détriment des conservateurs, mais aussi, sur le littoral, au détriment des républicains de gauche.

L'organisation politique de ce mouvement semble assez lâche et correspond bien au fonctionnement d'un parti de notables. La fédération départementale est dirigée dans les années 1930 par le docteur Louis Guillois qui est également membre du conseil national de la Fédération républicaine ${ }^{21}$. Une fiche de renseignement rédigée en 1943 le présente comme « l'un des éléments les plus en vue du parti URD dont il était le président de la Fédération départementale. A de l'influence et est très écouté dans les milieux catholiques ${ }^{22}$ ". Ce grand notable domine en effet la vie politique morbihannaise à la fin des années 1930. En 1904, il entre au Conseil municipal de Ploërmel, il en prend aussitôt la direction (1904-1952). En 1907 il accède au Conseil général (1907-1952), en 1920 il est élu sénateur URD du Morbihan (1920-1932) puis député URD en 1932 (1932-1936). À l'issue des cantonales de 1937 et de la perte de deux sièges par les radicaux au profit d'un élu URD et d'un républicain de gauche, il accède à la prési-

19. André Siegfried, après avoir relevé le grand nombre des courants existant au sein de l'URD, souligne que " de cette matière hétérogène, une réaction chimique fait apparaître au moins trois couleurs, la couleur de la féodalité industrielle, celle du nationalisme intransigeant et celle de la défense sociale catholique ", SIEGFRIED, André, Tableau des partis en France, Paris, Grasset, 1930, p. 182-184, cité par REMOND, René, Les Droites en France, Paris, Aubier, 1982, p. 457.

20. Christian Bougeard, dans son article sur les parlementaires modérés en Bretagne, en exclut les élus de l'URD car ils conservent " une proximité avec les conservateurs des années 1920, ils incarnent dans les années 1930 une droite renouvelée, très virulente contre les élus de gauche... ", BougEARD Christian, "Itinéraires de parlementaires modérés en Bretagne des années 1920 aux années 1960 ", dans Roth, François (dir.), Les Modérés dans la vie politique française (1870-1965), PUN, Nancy, 2000, p. 209-223. Dans le Morbihan, les candidats de l'URD font encore liste commune avec les conservateurs royalistes aux élections sénatoriales de 1920. La rupture date d'octobre 1923 lorsque les républicains URD décident d'exclure Gustave de Lamarzelle de la liste de droite pour les élections sénatoriales du 6 janvier 1924 .

21. Renseignement emprunté à Christian BOUGEARD, "Les notables et les forces politiques de droite en Bretagne dans les années 1930 ", dans "La recomposition des droites dans les années 1930 ", Annales de Bretagne et des Pays de l'Ouest, tome 109, n 3, 2002, p. 126. Il avait débuté sa carrière politique sous la bannière de l'Action libérale populaire en 1910. En 1912, il entre à la Fédération républicaine indépendante (FRI) et en devient le vice-président départemental, dans Audren, Denis, Le Morbihan et la République au travers des élections cantonales 1883-1914, mémoire de maîtrise, Vannes, 1998, p. 143.

22. Fiche confidentielle de renseignement adressée au préfet du Morbihan et datée de l'année 1943, Arch. dép. du Morbihan 2W11056. 
Carte 3 - Élections municipales de 1945 : étiquettes politiques des maires du Morbihan

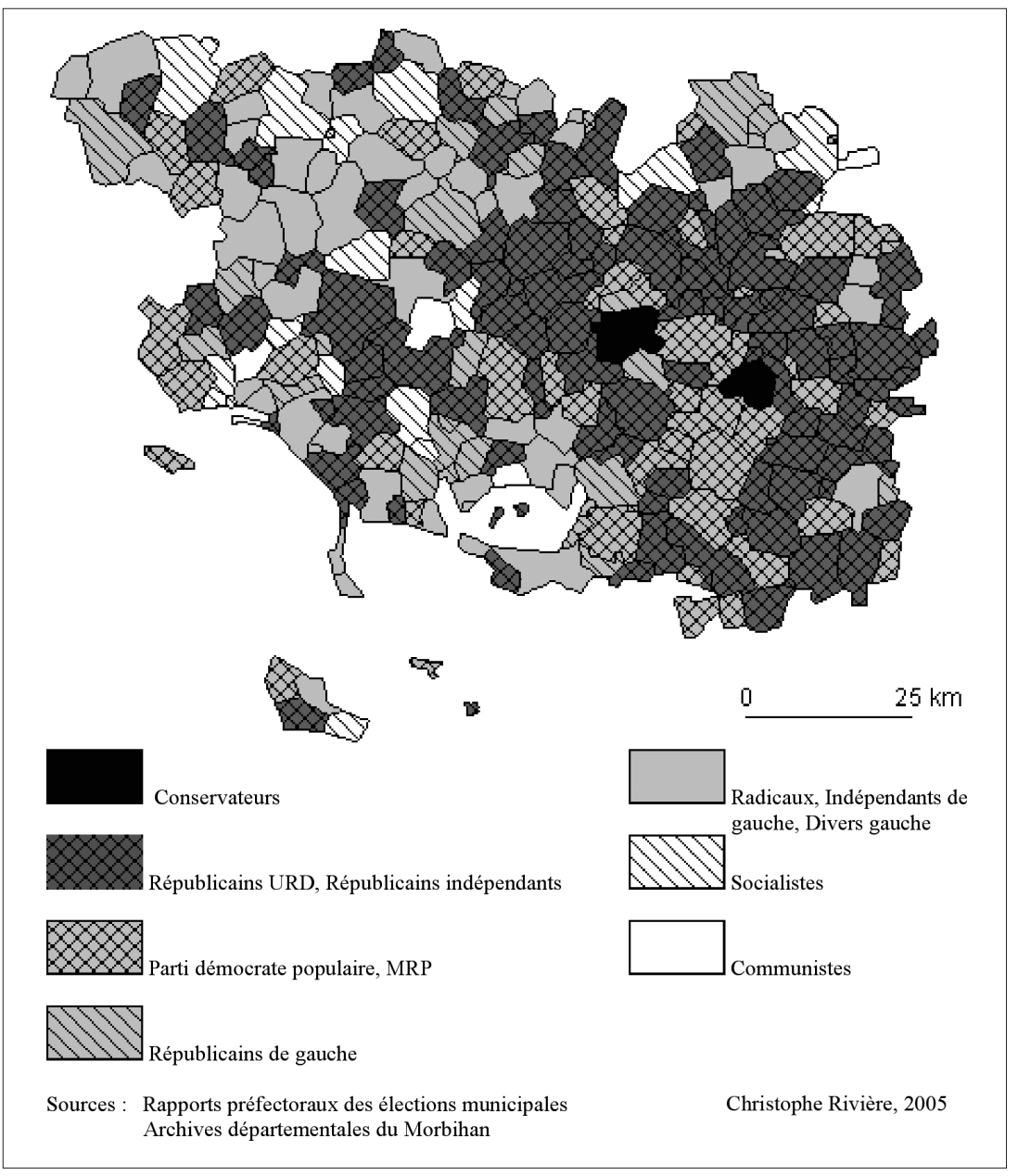

dence du Conseil général. Sous le régime de Vichy, il préside la Commission administrative (1942-1943), puis le Conseil départemental (1943-1944).

Ces notables partagent la vision traditionnelle de la société rurale qui caractérise les conservateurs, et siègent ensemble dans les structures dirigeantes de l'Union des syndicats agricoles de la Bretagne méridionale. Ainsi, Pierre Gillet, conseiller général URD de Saint-Jean-Brévelay (1925-1961), maire de Saint-Jean-Brévelay (1927-1945) et député du Morbihan (1936), est membre de la Caisse régionale de réassurance de la Bretagne méridionale, de la Caisse mutuelle d'assurances sociales et de la Caisse d'allocations familiales agricoles de la Bretagne méridionale. Cependant, l'emprise des 
notables URD sur les structures d'encadrement du monde rural semble moins forte que celle des conservateurs. Cette constatation peut s'expliquer par les différences sociologiques de recrutement. Très majoritairement, les maires URD se présentent comme cultivateurs ou comme propriétaires exploitants alors que les conservateurs sont essentiellement des propriétaires. Nous avons ainsi pu calculer qu'en 1935, sur les 52 maires URD de l'arrondissement de Vannes, 51,9\% se présentaient comme cultivateur ou comme propriétaire exploitant. Les professions libérales et les industriels fournissent quant à eux $15 \%$ de ces élus, et les artisans et les commerçants, $5,7 \%{ }^{23}$. Moins disponibles que les propriétaires, ils doivent en outre subir une relative relégation de la part des propriétaires, souvent nobles, qui se cooptent entre eux dans les comités de direction.

\section{Des modérés à la recherche d'un espace politique}

Le mouvement démocrate chrétien fait son apparition, au niveau municipal, aux élections de 1935. Cet ancrage local profite de la dynamique insufflée par les deux députés démocrates populaires du Morbihan, l'abbé Desgranges (1928-1940) et Ernest Pezet (1928-1946), par ailleurs président de la fédération départementale du Parti démocrate populaire (PDP). Il totalise 4,59\% des étiquettes revendiquées par les élus municipaux. L'implantation de ce nouveau courant politique est facilitée par l'aide que lui apportent de nombreux jeunes prêtres. Le préfet explique ce phénomène par " la mystique confessionnelle doublée d'un esprit social avancé $^{24}$ " de ce nouveau clergé. Cependant, les résistances à ce courant sont vives, même au sein du clergé, où les instances dirigeantes soutiennent plutôt le courant conservateur.

Ces élus se localisent principalement au cœur de l'arrondissement de Vannes (carte 1) et sur les pourtours de ce bloc conservateur. Il s'agit parfois de maires qui se reclassent et qui font ainsi basculer leur commune. À Elven, Pierre Lorgeoux est élu sous l'étiquette URD en 1929; puis en 1935, il adhère au PDP. Dans certains cas, il semble que cette évolution soit durable et que la commune puisse évoluer politiquement grâce à l'influence de l'édile. Cependant comme nous le verrons pour l'après-guerre, de nombreux reclassements politiques sont de courte durée et répondent plus volontiers à des calculs politiques; les électeurs conservent alors leurs traditions de vote.

Dans de nombreuses communes, les démocrates populaires s'implantent difficilement. Un rapport préfectoral souligne que les dirigeants du $\mathrm{PDP}$ " souhaitent une orientation centrale du parti républicain mais les troupes moins mobiles s'attardent dans leur classement original de blancs

23. Les renseignements manquent concernant les professions de 15 de ces 52 élus, soit $28,8 \%$ du corpus.

24. Rapport du préfet du Morbihan au ministre de l'Intérieur, le 6 avril 1935, Arch. dép. du Morbihan M4668. 
contre bleus $^{25}$ ". L'implantation des modérés dans le département se heurte donc à une bipolarisation de la vie politique, et leur culture de la négociation leur permet difficilement de se positionner entre le candidat de gauche, anticlérical et le candidat de droite, clérical.

Les élus républicains de gauche appartiennent aussi à cette mouvance modérée. Ce courant de centre-gauche est puissant dans le département durant les années 1920. En 1929, 23,37 \% des maires se rangent sous ses couleurs. Mais, à partir des années 1930, il décline sensiblement, passant ainsi de 14,55\% en 1935 à 9,19\% en 1945 pour enfin totaliser 4,19\% en 1947 avant de disparaître. Son ancrage correspond au mouvement de républicanisation du département constaté déjà par André Siegfried ${ }^{26}$, mouvement qui rogne le bloc conservateur sur ses marges, notamment au sud, près des côtes, là où l'influence économique et sociale de la noblesse est bien moindre que dans l'intérieur des terres. Les cantons de Guer, de La TrinitéPorhoët et de Mauron, au nord de l'arrondissement de Vannes, sont également concernés par ce phénomène. En 1935, dans l'arrondissement de Vannes, ces élus perdent des mairies au profit de candidats de droite, conservateurs, républicains URD et même des démocrates chrétiens ${ }^{27}$. Cependant le déclin des républicains de gauche profite essentiellement au radicalisme, voire au socialisme, après 1945. Le phénomène est sensible sur les communes littorales et surtout dans les terres : Augan, Réminiac, Ploemel, Locoal-Mendon se dotent ainsi de maires radicaux-socialistes ${ }^{28}$.

\section{Une gauche minoritaire mais conquérante}

Dans cette période de l'entre-deux-guerres, l'essentiel de la gauche morbihannaise est composée au niveau municipal par les radicaux-socialistes. Sur le pourtour du bloc oriental, ils succèdent souvent aux élus républicains de gauche. On remarque aussi un très net mouvement de conquête des régions situées au nord-ouest du département. Régions qui permettent la carrière d'Alfred Brard, conseiller municipal radical-socialiste de Pontivy (1895-1896), conseiller général du canton de Guéméné-sur-Scorff (19051937), président du Conseil général (1921-1936), député (1910-1914) puis sénateur du Morbihan (1920-1940), ainsi que celle d'Eugène Raude, maire radical-socialiste de Guéméné-sur-Scorff (1919-1942), député (1928-1936) et conseiller général de Guéméné-sur-Scorff (1937-1940). Ces deux grands notables sont les plus influents de la fédération départementale radicale

25. Rapport du préfet du Morbihan au ministre de l'Intérieur, le 16 mai 1935, Arch. dép. du Morbihan M4668.

26. SIEGFRIED, André, Tableau politique de la France de l'Ouest, op. cit., p. 182-183.

27. Notamment, en 1935, Beignon et La Trinité-Porhoët passent au Parti démocrate populaire, Néant-sur-Yvel passe aux républicains URD, Surzur et Péaule aux conservateurs.

28. Pour replacer ce courant modéré dans une perspective régionale on verra l'ouvrage de Patrick PIERRE, Les Bretons et la République. La construction de l'identité bretonne sous la Troisième République, Rennes, PUR, 2001, notamment les pages 252-254 qui développent le centrisme dans l'entre-deux-guerres et sa progression dans le Morbihan. 
et radicale-socialiste; avec Alphonse Rio, le seul élu morbihannais ayant une carrière ministérielle dans les années $1930^{29}$. Cette implantation s'appuie sur une propagande républicaine organisée par les réseaux de la gauche laïque et par ceux des milieux industriels et commerçants ${ }^{30}$.

Ces notables radicaux réussissent, à la différence des socialistes et plus encore des communistes, à mettre en place des réseaux liés au syndicalisme agricole. Le cas de Paul Lotz est significatif de cette interpénétration qui existe entre les structures agricoles et une carrière politique. Il est élu maire radical-socialiste de Saint-Aignan (1904-1947), il siège au Conseil général (1910-1935) et à la Chambre des députés (1932-1936). Il siège également au Conseil d'administration de l'École nationale d'agriculture de Rennes (1921). En 1911, il est nommé vice-président de la Caisse départementale du Crédit agricole du Morbihan. Il préside de très nombreux syndicats et sociétés ; citons parmi les plus influents : la Société départementale d'agriculture, l'Office agricole départemental (1919), la Caisse immobilière du Morbihan, le Syndicat des agriculteurs de Morbihan, l'Association des syndicats d'élevage du Morbihan. Le 24 décembre 1944, il prend la présidence du Comité d'action agricole qui succède à la Corporation paysanne de Vichy. On retrouve ainsi dans le département l'opposition entre les syndicats agricoles de la Bretagne méridionale affiliés à l'Union centrale de la rue d'Athènes à Paris, aux mains des conservateurs, et les syndicats agricoles rattachés au boulevard Saint-Germain à Paris et animés par des notables républicains.

La fréquence des phénomènes d'interdépendance entre les élus locaux, les parlementaires et les ministres radicaux, est également l'une des raisons que l'on peut avancer pour expliquer la percée du radicalisme dans le département ${ }^{31}$. Les services rendus par les parlementaires qui font le siège des ministères pour faire avancer des projets locaux doivent en retour susciter un soutien sans faille des élus municipaux, notamment au moment des élections sénatoriales. Cela transparaît dans un rapport du préfet où ce dernier développe les résultats des élections sénatoriales de 1932 et la victoire de deux radicaux-socialistes, Alphonse Rio et Alfred Brard. Il explique que leur élection est en partie due à l'appoint de voix personnelles

29. Jacqueline SAINCLIVIER explique les débuts de sa carrière ministérielle par son appartenance aux réseaux se développant dans le sillage d'Aristide Briand, dans "La légitimité politique des députés bretons de l'entre-deux-guerres : approche prosopographique ", L'Ouest et le politique, Rennes, PUR, 1996, p. 158 sqq.

30. Par exemple, Alfred Brard, issu d'une famille d'industriels et de négociants, dirige une distillerie à Pontivy. Eugène Raude est pharmacien à Guéméné-sur-Scorff, il possède des parts dans une coopérative pharmaceutique de Melun ayant une succursale à Nantes ainsi que des parts de pêche dans certains bateaux de Lorient. Il est également vice-président de l'Union nationale des pharmaciens français. Eugène Raude est par ailleurs membre de la Franc-maçonnerie. en 1942, il est démis de ses fonctions en raison de l'application de la loi sur les sociétés secrètes.

31. À ce sujet voir Serge Berstein, Histoire du Parti radical, Paris, PFNSP, 1980-1982, p. $296 s q q$. 
"résultant des services rendus aux hommes et aux collectivités communales pendant de longues années ${ }^{32} \ldots$ "

S'appuyant sur les bastions ouvriers de la région lorientaise, deux socialistes sont réélus en 1929. À Lorient, Emmanuel Svob, conseiller municipal depuis 1919, est élu maire en 1925 à la tête d'une liste intitulée Cartel des gauches, regroupant 18 candidats socialistes et 14 radicaux-socialistes dissidents en rupture avec la liste radicale officielle des députés Bouligand et Labbès. Pierre Rogel, conseiller municipal (1909) puis maire SFIO de Lanester depuis 1919 et conseiller d'arrondissement depuis 1929, est le second maire SFIO du département en 1929. En 1935, deux autres maires de la région lorientaise accentuent l'ancrage du mouvement socialiste dans le département, Jean Le Maux à Keryado et Emmanuel Le Visage à Locmiquélic, qui succèdent tous deux à des maires radicaux. L'implantation des socialistes et des quelques conseillers municipaux communistes se limite donc aux communes ouvrières. Les tentatives de percée dans le Morbihan rural se soldent par des échecs. Le meilleur exemple est sans doute celui de Jean-Louis Le Coutaller, directeur de l'école publique de Persquen présent dans de très nombreux scrutins (municipaux, cantonaux et législatifs) dans les années 1930, et qui cumule les insuccès. Il ne perce politiquement qu'après 1945, profitant du contexte général favorable aux forces de gauche et de son engagement actif dans la Résistance ${ }^{33}$.

Le département présente donc, au regard des résultats des élections municipales, un rythme politique propre et qui paraît décalé des grands enjeux nationaux ${ }^{34}$. La dynamique du Front populaire est difficile à repérer, même si la SFIO double le nombre de ses maires en 1935. Au sein des courants de droite ${ }^{35}$, l'impact des ligues paraît très limité ${ }^{36}$. L'Action française, dont le recrutement s'opère majoritairement dans les milieux aristocratiques et parmi les officiers en retraite, joue un rôle politique négligeable, se contentant sur la période d'organiser quelques réunions privées et des messes le 21 janvier. L'agitation dorgériste, qui prend une certaine ampleur dans le Morbihan grâce à l'implantation de comités de défense

32. Rapport du préfet du Morbihan au Ministre de l'Intérieur daté du 6 avril 1935, Arch. dép. du Morbihan M4668.

33. En 1945, il est élu conseiller général SFIO de Gourin et député de la circonscription de Pontivy jusqu'en 1956. En 1953, il est élu maire de Lorient.

34. Cela s'explique en partie par " la nature même des assemblées concernées qui tend à amortir les chocs politiques et favorise une diversité d'alliances plus difficile à imaginer nationalement ", citation empruntée à Robert MENCHERINI, «Les changements des rapports de forces politiques ", dans Le Beguec, Gilles et Peschanski, Denis (dir.), Les Élites locales dans la tourmente. Du Front populaire aux années cinquante, Paris, Éditions du CNRS, 2000, p. 36.

35. Pour une vision régionale des rapports politiques au sein des droites, il faut voir la synthèse de Christian Bougeard, "Les notables et les forces politiques de droite en Bretagne dans les années 1930 ", op. cit., p. 121-139.

36. Sur la question des ligues dans le département voir MALHERBE, Marie-Christelle, Les Croix de Feu, le Parti Social Français, le Parti Populaire Français en Morbihan, mémoire de maîtrise, Rennes 2, 1989. 
paysanne $^{37}$, semble rapidement circonscrite par les milieux de l'USABM qui limitent son espace d'expression politique. En revanche, le Parti social français (PSF) enregistre des succès plus probants au niveau local. Des maires prennent la tête de sections municipales, comme à Elven ou à l'île aux Moines, et quatre conseillers d'arrondissement adhèrent au mouvement en octobre $1937^{38}$. C'est donc clairement une impression de stabilité qui domine quand on observe le corpus des maires morbihannais au cours des années 1930. Cependant, des évolutions sur le long terme peuvent être repérées. Au niveau local, le processus de républicanisation, amorcé au début de la Troisième République, semble s'achever dans les années 1930, avec, au sein des droites, une domination très nette de la droite républicaine sur la droite monarchiste conservatrice ${ }^{39}$. Le corpus des maires morbihannais semble donc plus réactif aux problématiques régionales qu'au contexte national dans les années de l'entre-deux-guerres; à partir de 1940, le contexte général va influer de manière plus forte sur la vie municipale.

\section{Les maires du Morbihan dans la tourmente, 1940-1945}

\section{Vichy et l'Occupation, source nouvelle de légitimité pour les édiles?}

L'épisode de la guerre et surtout de l'Occupation va renforcer l'influence des notables sur la communauté villageoise; car les difficultés, les craintes et les angoisses se multiplient, et le maire reste souvent le seul recours, le seul rempart contre les malheurs du temps.

Sous la Troisième République, le maire était sollicité par ses administrés pour faciliter le règlement de certaines questions personnelles avec l'administration. Pendant la Seconde Guerre mondiale, les difficultés liées à l'Occupation et surtout l'intransigeance et la sévérité des autorités allemandes, font que l'intervention du maire concerne des affaires dont les conséquences sont beaucoup plus graves; il en résulte que les espérances dans la médiation du maire sont beaucoup plus fortes. On pourrait dire, en se plaçant du point de vue des notables, que cette évolution, en confortant leurs positions, est plutôt positive. Cette évolution s'insère évidemment dans la doctrine élitiste de l'État français. Un rapport du Conseil d'administration de l'Association des maires du Morbihan, daté de 1943,

37. Nous en avons recensé 7 pour l'arrondissement de Vannes; sur cette question on se reportera à l'étude de Maryvonne PEDRONO, Le Morbihan au temps des fourches. Le dorgérisme dans le Morbihan dans les années 1930, mémoire de maîtrise, Rennes 2, 1996.

38. Chiffre repris de l'article de Jean-Paul ThomAs, "Le Parti social français ", dans $L a$ genèse du RPF, Paris, Cahiers de la Fondation Charles de Gaulle, n 4, 1997, carte p. 75.

39. Sur le mouvement de républicanisation en Bretagne on se reportera à l'ouvrage de Patrick PIERRE, Les Bretons et la République. La construction de l'identité bretonne sous la Troisième République, op. cit., notamment les pages 198 et suivantes où il développe l'exemple du Vitréen qui semble assez proche dans ses structures sociales et dans ses comportements politiques de la partie orientale du Morbihan. 
résume la place nouvelle que sont appelés à jouer les maires sous le régime de Vichy :

" [...] Le maire a aussi un rôle moral à remplir, plus important peut-être que tous les autres, surtout dans cette triste époque où tous les Français n'ont malheureusement pas compris le grand devoir d'union. Il se doit à tout et à tous. Pour son sang-froid, sa sérénité d'esprit et sa fermeté de caractère ses concitoyens doivent le considérer comme leur guide et leur directeur de conscience ${ }^{40}$."

Le pendant de ce renforcement de l'autorité du maire est la complication de sa tâche face aux exigences de deux intervenants, les troupes d'occupation et le régime de Vichy. La conjoncture générale est marquée par des pénuries dans les communes urbaines et par des réquisitions dans les campagnes. Cependant, c'est l'afflux des réfugiés, qui commencent à arriver dans le département à partir du 10 mai 1940, qui marque les premiers temps de la guerre ${ }^{41}$. La gestion de ces flux d'arrivants, auxquels il faut ajouter, dans certaines communes, les troupes d'occupation, nécessite des efforts considérables de la part des maires pour les loger et les nourrir convenablement. Les tensions ayant pour origine les réquisitions de logements apparaissent. Mais ce sont les réquisitions de productions agricoles qui génèrent les premiers conflits sérieux.

Les réquisitions agricoles furent sévères, les autorités allemandes imposaient des prélèvements lourds aux communes morbihannaises ${ }^{42}$. Les municipalités et les structures corporatistes avaient la charge d'honorer les quantités exigées. La position des maires va rapidement devenir inconfortable; ils vont en effet subir les reproches et parfois les menaces des autorités vichystes et allemandes lorsque les contingents ne sont pas livrés, et ils vont focaliser la colère des agriculteurs, peu désireux de voir une partie de leur production réquisitionnée. Sans conteste, les difficultés liées à la mise en place des réquisitions sont à l'origine de nombreuses démissions et révocations. Comme le rappelle un rapport du secrétaire général de la préfecture, les maires consentent à conserver, en matière de ravitaillement, la distribution du pétrole, des bougies, des pneus, parfois du

40. Rapport du Conseil d'administration de l'Association des maires du Morbihan adressé au préfet du Morbihan et daté du 6 avril 1943, Arch. dép. du Morbihan 2W12599.

41. Le Morbihan en accueille 144135 pour une population de 542000 habitants. Ces chiffres sont repris de l'ouvrage dirigé par Gérard LE BouEDEC, Le Morbihan de la Préhistoire à nos jours, Saint-Jean-d'Angély, Bordessoules, 1994, p. 372. Ces premiers réfugiés de la guerre repartent à la fin de l'été 1940. En septembre 1943, un rapport du secrétaire général de la préfecture fait état de 52000 réfugiés lorientais après la destruction de leur ville. Environ 30000 de ces réfugiés restent dans le département, les autres trouvent refuge en Seine-et-Marne, en Mayenne et en Indre-et-Loire. Il faut aussi rajouter les réfugiés qui fuient les bombardements de Saint-Nazaire et dont une partie s'installe dans les cantons sud-est du département. Rapport du secrétaire général de la préfecture du Morbihan au préfet du Morbihan daté du 25 septembre 1943, Arch. dép. du Morbihan 2W12599.

42. On trouvera un développement complet sur ces questions dans Roger LEROUX, Le Morbihan en guerre. 1939-1945, Mayenne, Imprimerie de la Manutention, 1991, p. 231 sqq. 
textile et des chaussures à leurs administrés, car cela " constitue pour eux un moyen de gouvernement, par lequel ils affirment leur puissance aux yeux des habitants ${ }^{43}$ ". Mais ils rejettent l'obligation d'avoir à répartir les impositions diverses en produits de l'agriculture.

" En la matière l'impopularité dépasse la puissance, sans compter l'ennui d'avoir à s'imposer lourdement pour donner l'exemple. Or nos maires restent soucieux, à des degrés divers, et à part quelques exceptions d'un absolu dévouement au bien public, de leur petite popularité. Comment la conserver en obligeant Pierre et Paul à livrer céréales, bestiaux et pommes de terre $[\ldots]^{44}$."

Le Service du Travail obligatoire (STO) est le second élément qui va singulièrement compliquer la tâche des maires, en les obligeant à désigner des travailleurs. La première opération de relève date de septembre 1942 dans le département. C'est essentiellement vers l'organisation Todt, qui réclame des ouvriers pour œuvrer sur ses chantiers côtiers et plus précisément lorientais, que sont dirigés les requis morbihannais. Roger Leroux cite ainsi une note de la Feldkommandantur de Vannes exigeant que 600 travailleurs soient mis à disposition de cette organisation pour le 23 janvier $1943^{45}$. Certains maires se résignent à accomplir ces désignations, d'autres comme à Ploërmel, tirent au sort les requis, certains désignent des agriculteurs qui sont exemptés de réquisitions et cinquante maires refusent de procéder à ces désignations. À Elven par exemple, le maire de tendance URD, nommé par Vichy en 1942 et conseiller départemental (1943-1944), offre sa démission car il " refuse de désigner des travailleurs pour l'Organisation Todt ${ }^{46}$ ".

La guerre favorise donc une évolution de la place du maire dans la commune. Cette évolution est imposée autant par les autorités administratives et par les troupes d'occupation que par le contexte exceptionnel de la période. Les maires semblent accepter dans un premier temps les nouveautés visant à assurer un meilleur contrôle des populations mais à mesure de l'impopularité croissante des tâches que les autorités veulent leur faire accomplir, ils se montrent beaucoup moins coopérants. Un rapport du Conseil d'administration de l'Association des maires du Morbihan, tenu à l'hôtel de ville de Vannes en avril 1942, décrit très justement ces changements :

" [Le maire] ne pourra être porteur d'union que dans la mesure où il jouira de la confiance de ses concitoyens, et cette confiance ne lui sera accordée que dans la mesure où il apparaîtra à tous comme le défenseur de la cité et non comme un agent de la force publique. La confiance que manifestent ses concitoyens à l'égard du maire disparaît surtout du fait de la réglementation qui contraint ce dernier à effectuer lui-même la mobilisation

43. Arch. dép. du Morbihan 2W12599, Rapport du secrétaire général de la préfecture adressé au préfet du Morbihan et daté du 25 juillet 1942.

44. Arch. dép. du Morbihan 2W12599, idem.

45. LEROUX, Roger, Le Morbihan en guerre, 1939-1945, op. cit., p. 235.

46. Rapport du préfet du Morbihan au ministère de l'Intérieur, daté des mois de novembre et décembre 1943, Arch. dép. du Morbihan 2W11052. 
de la main d'œuvre réclamée par les troupes d'occupation et la réalisation des produits agricoles ${ }^{47}$."

\section{Les maires et la Révolution nationale}

Le Régime de Vichy promeut les élites traditionnelles qui doivent reprendre en main la société. Cette idéologie élitiste rencontre évidemment un écho favorable chez les élus morbihannais. Ces derniers accueillent favorablement le nouveau régime, ainsi 96,56\% des municipalités votent des motions de confiance au maréchal Pétain en février $1941^{48}$. Cette opération consciencieusement suivie par l'administration préfectorale montre bien l'attachement des notables à la personne du maréchal. À cette date, seules 9 communes n'ont pas encore voté ces motions. Trois de ces communes sont dirigées par des élus de droite, 2 par des membres du PDP et 4 par des radicaux-socialistes. Il est donc difficile de conclure à une fronde politique menée par les forces de gauche contre le nouveau régime ${ }^{49}$.

Il faut néanmoins relativiser l'importance du vote des motions de confiance; certes elles illustrent le bon accueil réservé au maréchal Pétain, mais ces votes revêtent des motivations polysémiques. En effet, on peut distinguer parmi les maires, ceux qui à la suite de Charles Maurras célèbrent la " divine surprise " de 1940 et ceux qui, sans adhérer forcément au projet politique de Vichy, se reconnaissent dans la personne du maréchal Pétain, héros de la Première Guerre mondiale. En octobre 1941, les sous-préfets de Lorient et de Pontivy rédigent un rapport destiné au préfet ${ }^{50}$ où ils tentent de mesurer l'adhésion des maires au nouveau régime. Dans l'arrondissement de Pontivy, 21 maires sur 80 sont comptabilisés comme «favorables et ralliés à la politique de Rénovation nationale ", ils sont 24 sur 61 dans l'arrondissement de Lorient, soit $31,91 \%$ des élus de ces deux arrondissements ${ }^{51}$. Les autres élus se répartissent dans deux autres catégories, ceux qui adoptent " une attitude correcte mais n'ont pas d'activité politique », 6 pour l'ar-

47. Rapport du Conseil d'administration de l'Association des maires du Morbihan adressé au préfet du Morbihan et daté du 6 avril 1943, Arch. dép. du Morbihan 2W12599.

48. Christian BougEARD cite le chiffre de $97 \%$ au premier avril 1941, "La Bretagne ", dans AzEMA, Jean-Pierre et BEDARIDA, François (dir.), Vichy et les Français, Paris, Fayard, 1992, p. 536 .

49. Seul le maire URD de Bangor, dans l'arrondissement de Lorient, justifie sa position auprès de la préfecture. Selon un compte rendu effectué par le sous-préfet de Lorient, il refuse d'accorder sa confiance en raison "de la condamnation à mort de monsieur le général de Gaulle et du vice-amiral de Larminat ". Après une visite du sous-préfet, François Le Marec accepte de revenir sur sa décision, afin de " faire un geste dans le cadre de sa commune pour réaliser l'union préconisée sur le plan national. " Le 16 mars 1941, il peut envoyer une nouvelle délibération du Conseil municipal où il exprime son respect pour le chef de l'État. Rapport du sous-préfet de Lorient au préfet du Morbihan, le 11 mars 1941, Arch. dép. du Morbihan 2W15733.

50. Rapports des sous-préfets des arrondissements de Lorient et de Pontivy datés d'octobre 1941, Arch. dép. du Morbihan 2W10780.

51. Il faut en outre y ajouter les maires de l'arrondissement de Vannes qui accueillent encore plus favorablement, semble-t-il, le nouveau régime. 
rondissement de Pontivy et 9 pour celui de Lorient soit 10,63\%, et une majorité de $57,45 \%$ des maires qui n'apparaissent pas dans le rapport et dont on peut supposer qu'ils adoptent un comportement très réservé.

L'accueil de l'État français par les notables peut également se mesurer à l'aune de leur investissement dans les différentes structures mises en place par le nouveau régime. En ce qui concerne les cantons de Rohan, Josselin et Cléguérec dans l'arrondissement de Pontivy, nous possédons la liste des syndics locaux de la Corporation paysanne ${ }^{52}$. Si on prend en compte le fait que cette institution est plus en phase avec les attentes des élites paysannes morbihannaises de droite par rapport à l'œuvre de propagande sociale ou encore par rapport à la Commission administrative ou au Conseil départemental aux places limitées, nous avons là un bon exemple de ce qu'a pu être l'investissement des notables dans les instances de Vichy. En outre, ces cantons offrent des situations politiques différentes. Le canton de Cléguérec appartient au pôle radical du nord-ouest du département, le canton de Rohan est composé à la fois de communes votant à gauche et de communes votant à droite, ces dernières étant majoritaires. Et le canton de Josselin appartient au môle conservateur de l'est du Morbihan. Sur les 24 syndics communaux, 4 cumulent avec la fonction de premier magistrat de la commune : le maire conservateur de Lanouée pour le canton de Josselin, le maire URD de Lantillac pour le canton de Rohan, le maire conservateur de Neuillac et le maire URD de Sainte-Brigitte pour l'arrondissement de Cléguérec.

La proportion des maires est donc à la fois significative $(16,66 \%)$ du rôle que Vichy entend faire jouer aux édiles locaux, mais aussi finalement assez limitée pour un régime qui entend s'appuyer sur les notabilités. Il semble que dans le cadre de la Corporation paysanne, d'autres élites locales soient mises en avant, il s'agit plutôt, d'après nos premières constatations, d'agriculteurs ou de propriétaires engagés dans les structures de l'USABM $^{53}$. L'analyse peut être complétée par l'étude des structures départementales. Ainsi, pour les instances appelées à remplacer le Conseil général, on compte 5 maires sur 9 membres de la Commission administrative du Morbihan qui fonctionne du $1^{\text {er }}$ février 1941 au 7 août 1942 et 18 maires sur 32 membres du Conseil départemental ${ }^{54}$.

L'investissement des maires dans les organisations de l'État français est donc inégal, il est important dans les structures départementales et moins évident dans la Corporation paysanne. Il est donc difficile de mettre en avant, à partir de ce corpus, l'image du notable type favorisé par Vichy.

52. Cette liste est datée de juin 1942, Arch. dép. du Morbihan 2 W15731.

53. On retrouve globalement le même phénomène dans le Finistère et les Côtes-du-Nord avec une très nette domination de l'Office central de Landerneau analysé par Suzanne BERger, Les Paysans contre la politique, op. cit., p. 171 sqq. Cependant dans le cadre du Morbihan, cette question mériterait une analyse plus approfondie.

54. Il faudrait y ajouter également les structures de la propagande sociale du Maréchal qui restent à étudier dans le département. 


\section{La Rénovation nationale à l'échelon communal}

Le régime de l'État français réforme la législation régissant les municipalités françaises. Les lois du 16 novembre 1940 prévoient que le Conseil municipal, les adjoints et le maire restent éligibles, selon le régime antérieur, pour les communes de moins de 2000 habitants ${ }^{55}$. Pour les communes de plus de 2000 habitants, le Conseil municipal, les adjoints et le maire sont nommés. Selon la taille des villes, les autorités se chargeant des nominations diffèrent. Dans les villes de plus de 10000 habitants c'est le ministre secrétaire d'État à l'Intérieur qui nomme le maire. Dans les communes de 2000 à 10000 habitants, cette tâche incombe au préfet. Pour les adjoints les critères de nomination sont les mêmes, mais pour les conseillers municipaux la compétence des préfets s'étend jusqu'aux villes de 50000 habitants ${ }^{56}$.

Dans le cadre de la politique mise en place dans les débuts du régime de Vichy, l'union des tendances autour du chef charismatique explique le projet du préfet Piton qui tente un rassemblement des forces politiques, communistes exceptés. Le préfet Piton, nommé en 1936 dans le Morbihan, tente de " grouper autour du gouvernement de M. le Maréchal Pétain, dans un large esprit d'union, toutes les bonnes volontés, à quelque parti qu'elles appartenaient ${ }^{57}$ ". Ce projet vise à rééquilibrer les municipalités issues des élections de 1935. Dans les conseils municipaux dominés par la gauche, il désire faire entrer des représentants des partis de droite et dans les municipalités administrées par la droite, il souhaite que des éléments de gauche, "favorables au gouvernement ", soient représentés. Ce projet de rassemblement ne voit pas le jour en raison de l'intransigeance de certaines personnalités de droite et notamment de Roger Grand, sénateur du Morbihan (1927-1932), conseiller national, président d'honneur de la Société d'histoire et d'archéologie de Bretagne et professeur à l'école des Chartes. Il désire remplacer toutes les municipalités de gauche par des municipalités de droite. Il paraît donc clair qu'au-delà des velléités d'union affichées par le gouvernement de l'État français, on assiste à un rejet d'une partie de la classe politique, rejet motivé à la fois par une volonté affichée de combattre l'anti-France et par l'esprit de revanche qui anime certains élus de la droite au niveau local. Le cas ici de Roger Grand est tout à fait éclairant des pressions que peuvent subir les préfectures.

55. Jean-Paul Cointet, dans sa synthèse sur la période, rappelle que le principe de l'élection subsiste dans 35000 des 38000 communes françaises, en définitive les campagnes, censées être plus favorables au nouveau régime, sont plus épargnées dans un premier temps par les remaniements, dans CoINTET, Jean-Paul, Histoire de Vichy, Paris, Plon, 1996, p. 122-123.

56. Les procédures de nomination des nouveaux maires ou des présidents de Délégation spéciale vont évoluer sous Vichy, notamment par les lois des 13 novembre 1941, 4 octobre 1943 et 7 avril 1944, qui globalement renforcent les pouvoirs des préfets dans les nominations au sein des conseils municipaux, on se référera à ce sujet à FougERE, Louis et MACHElon, Jean-Pierre, MonNiER, François (dir.), Les Communes et le pouvoir de 1789 à nos jours, Paris, PUF, 2002, p. 480-482.

57. Rapport du préfet du Morbihan, sans date, Arch. dép. du Morbihan 2 W15743. 
Si dans la plupart des cas, les maires ne sont pas inquiétés par le régime pétainiste et restent en place, certains d'entre eux vont cependant faire les frais d'une épuration politique. Cette épuration va rester limitée, car elle ne concerne que $9,19 \%$ des maires du département. Cependant, au cours de la Seconde Guerre mondiale, 98 communes sont concernées par un changement à la tête de leur Conseil municipal, ce qui représente près de $37,54 \%$ des municipalités. Près de 115 maires ou présidents de Délégation spéciale ${ }^{58}$ se succèdent à la tête des mairies. Ce corpus est suffisamment large pour appréhender la nouvelle élite politique que Vichy tente de mettre en place.

Tableau 2 - Étiquettes politiques des maires de Vichy et des maires de la Libération

\begin{tabular}{|l|c|c|c|}
\hline & $\begin{array}{c}\text { Maires élus } \\
\text { avant 1940 }\end{array}$ & $\begin{array}{c}\text { Maires nommés } \\
\text { sous Vichy }\end{array}$ & $\begin{array}{c}\text { Maires nommés } \\
\text { à la Libération }\end{array}$ \\
\hline SFIO & 3 & 3 & 3 \\
Radicaux & 29 & 19 & 13 \\
Républicains de gauche & 15 & 10 & 8 \\
PDP & 3 & 1 & 4 \\
MRP 59 & - & 8 & 3 \\
Républicains indépendants & - & - & 1 \\
URD & 21 & 33 & 10 \\
Conservateurs & 23 & 7 & 1 \\
PSF & - & 1 & - \\
Sans étiquette & - & 3 & 13 \\
Inconnus & 21 & 30 & 56 \\
\hline Total & 115 & 115 & \\
\hline
\end{tabular}

L'étude du tableau 2, qui compare les étiquettes politiques des maires élus avant 1940 avec ceux nommés sous le régime de Vichy, montre un net virage à droite, en adéquation avec l'esprit de la Révolution nationale. Lorsque l'on additionne les maires socialistes, radicaux et républicains de gauche on s'aperçoit qu'ils représentent 49,56 \% des élus qui changent à la tête des municipalités. Ils ne sont remplacés qu'à hauteur de 27,82 \% par des notables de la même couleur politique sous Vichy. Les grands gagnants de ces changements sont les républicains URD, qui profitent de la perte d'influence de la gauche, mais aussi d'une sensible désaffection pour l'étiquette conservatrice. Il est à noter que peu de maires adoptent une neutralité politique, pourtant plus en phase avec le rejet des partis politiques, symboles d'une Troisième République que l'on veut oublier.

58. Les délégations spéciales sont mises en place lorsque l'ensemble du Conseil municipal est dissous, à ce sujet voir FougERE, Louis, MACHELON, Jean-Pierre et MonNIER, François (dir.), Les communes et le pouvoir de 1789 à nos jours, op. cit., p. 481.

59. Il s'agit de maires nommés sous Vichy et dont on ne connaît pas l'étiquette, mais qui à la Libération apparaissent sous la bannière du MRP. 
Lorsque l'on s'interroge sur les raisons de ces changements, on s'aperçoit que 20,86 \% d'entre eux sont le fruit d'une procédure de révocation. L'étude chronologique ${ }^{60}$ (Graphique 1) de cette politique coercitive montre que l'essentiel de ces mesures date des mois de novembre (1 révocation), décembre (4 révocations) 1940 et de janvier (2), mars (4) avril (1), juin (1) et août (1) 1941. On remarque deux pics, l'un en décembre 1940 et l'autre en mars 1941. Cette vague est à replacer dans la politique d'exclusion et de "régénération intérieure ${ }^{61}$ ". C'est donc sans surprise que nous relevons qu'elle concerne essentiellement des maires de gauche. Ainsi, $75 \%$ de ces 24 notables révoqués sont inscrits dans un parti de gauche; 3 militent à la SFIO, 12 sont des radicaux et 3 des républicains de gauche.

\section{Graphique 1 - Maires révoqués ou démissionnaires sous le Régime de Vichy, octobre 1940-mai 1944}

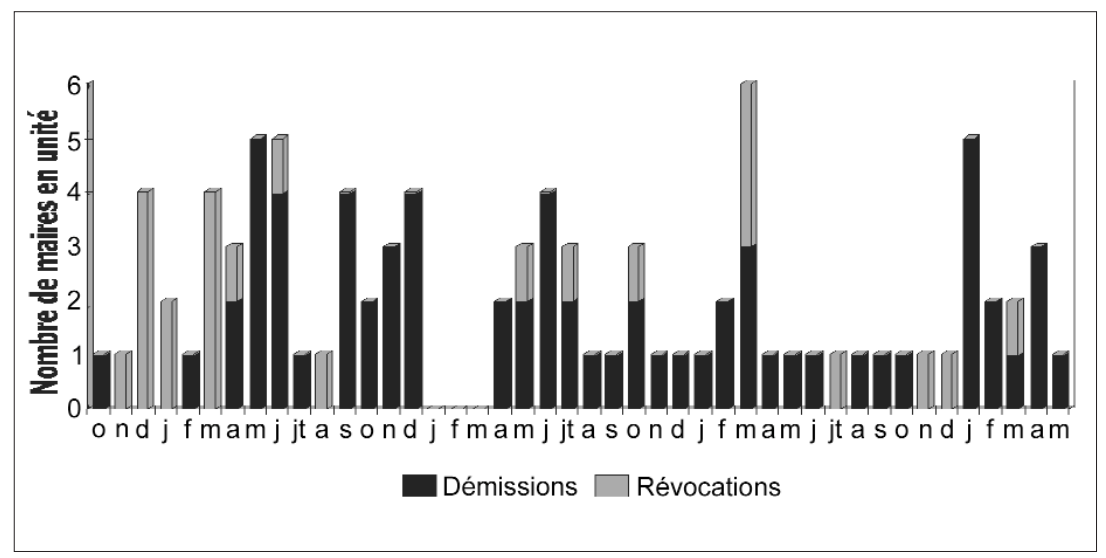

Les motivations de ces révocations sont multiples; pour $50 \%$ de ces maires il s'agit de raisons politiques, pour 16,66 \% c'est l'incompétence du maire qui est mise en avant, pour 4,16 \% c'est le maire qui abandonne son poste et enfin 16,66 \% des maires sont démissionnés sur ordre des autorités allemandes.

En ce qui concerne les révocations à caractère politique, elles sont globalement de trois ordres. Tout d'abord, dans le cadre de sa politique répressive, Vichy va s'attaquer à l'anti-France. Anti-France qui englobe les francsmaçons, les étrangers, les Juifs et les communistes. Les élus appartenant

60. Nous ne donnons ici que les dates de publication de la révocation au Journal Officiel. Il y a donc un délai entre la prise de décision et son application. En outre, il manque dans ces chiffres près de 10 maires pour lesquels nous ne possédons pas de date précise.

61. Nous empruntons cette expression à Denis Peschanski dans son introduction à la synthèse coordonnée par l'IHTP sur les élites locales dans la Seconde Guerre mondiale, dans Le Beguec, Gilles et Peschanski, Denis (dir.), Les Élites locales dans la tourmente. Du Front populaire aux années cinquante, op. cit., p. 21. 
à l'une ou l'autre de ces catégories sont exclus des instances de décision politique. Le maire radical-socialiste de Guéméné-sur-Scorff, Eugène Raude, membre de la franc-maçonnerie, est ainsi révoqué le 25 juillet 1942. Certains maires ne remplissent pas les nouvelles conditions formulées par la loi de novembre 1940 qui restreint l'accès aux fonctions édilitaires, notamment pour les maires qui ont été naturalisés français. C'est ainsi le cas du radical-socialiste Camille Herwegh, conseiller général (1922-1940), maire d'Hennebont depuis 1925, né de parents suisses à Donnersmark dans la région roumaine de Transylvanie et qui est naturalisé français en 1884 à l'âge de 12 ans. Il complète un dossier afin de bénéficier d'une exception, il argue de son engagement dans l'effort de guerre en 1914-1918 à la tête des forges d'Hennebont, ainsi que de la mort de son fils le 9 juin 1940 à la tête de son échelon de ravitaillement à Vauxcastille. Il met également en avant le fait que son gendre, le lieutenant Jean Gard, fait prisonnier par l'ennemi est, détenu en Allemagne. Mais ces preuves d'un réel patriotisme ne suffisent pas à faire réviser son dossier.

Cette politique se contente souvent, dans les rapports préfectoraux, de laconiques "sentiments hostiles à l'action du gouvernement ", sans que la décision soit expliquée dans les détails. Un bon exemple est fourni par le cas du maire radical indépendant de Vannes, Maurice Marchais. Ce dernier est dénoncé aux autorités pour avoir tenu des propos injurieux envers la personne du maréchal Pétain. Le rapport d'enquête de la police ${ }^{62}$ conclut à l'impossibilité de prouver les accusations. Néanmoins, cet opposant en puissance est démis de l'ensemble de ses mandats ${ }^{63}$.

Une seconde catégorie comprend les maires qui, par lassitude ou par manque d'autorité ou qui, faute des compétences de gestionnaire lors des situations de crise générées par la guerre et par l'Occupation, sont complètement dépassés par les événements. Mais même cette dernière catégorie, qui ne paraît pas participer d'un esprit d'épuration politique, réserve parfois des surprises lorsque les sources sont abondantes. Ainsi, en mai 1942, le maire radical-socialiste de Saint-Jean-la-Poterie est suspendu pour trois mois puis révoqué de ses mandats, car " il ne prend aucun soin de sa commune ${ }^{64}$ ". Trois documents d'archives retracent les étapes de cette décision. Le premier est une lettre du président de l'Union des syndicats d'artisans du Morbihan datée du 30 mars 1942. Dans ce document, il retrace les étapes de l'implantation par les services de l'artisanat d'une dizaine d'apprentis autour de quatre maîtres potiers, sur la

62. Joint au rapport du préfet du Morbihan au ministre de l'Intérieur daté du 4 janvier 1941, Arch. dép. du Morbihan 2W15742.

63. Pour une analyse plus poussée de cette affaire nous nous permettons de renvoyer le lecteur à notre étude, RIVIERE, Christophe, Approche de la légitimité des notables bretons. Éléments pour une étude des conseillers généraux de Bretagne, mémoire de DEA, Brest, UBO, 2002, p. 165.

64. Rapport préfectoral de synthèse sur les sanctions à l'égard des maires et des conseillers municipaux du Morbihan daté du premier mars 1943, Arch. dép. du Morbihan $2 \mathrm{~W} 10741$. 
commune de Saint-Jean-la-Poterie. Cette activité, jadis florissante dans ce village, a périclité. Grâce à une subvention du Secours national et au dynamisme d'un chef de mission, " qui a fait son apprentissage dans un des camps de jeunesse du maréchal ${ }^{65}$ ", cette activité peut redémarrer. Le président de l'Union se plaint rapidement de l'hostilité de certains éléments du Conseil municipal qui s'efforcent, selon lui, de contrecarrer cette entreprise. Le second document est un rapport de police qui tente de démasquer ces éléments. Il dresse une liste d'opposants; la secrétaire de mairie, par ailleurs directrice de l'école publique, l'ingénieur du Service vicinal de la Gacilly, la fille et les nièces du premier adjoint qui sont employées comme auxiliaires à la mairie. Dans ce rapport, le premier adjoint est décrit comme " un homme du Front populaire, il aurait appartenu au parti SFIO et depuis 1921 il est adhérent à la Ligue des droits de l'homme. Il déclare ouvertement que l'école laïque est l'école de la République française ${ }^{66}$ ». Enfin, le troisième document est une lettre du vicaire, l'abbé Le Cadre, qui dénonce l'arrêt de la location par la commune d'un terrain au club de football de la paroisse ${ }^{67}$. En mars 1942 , le bail n'est pas reconduit. On comprend alors mieux le processus qui a conduit à la révocation du maire de cette commune.

Ce cas d'école montre en effet que le camp de la gauche, bien implanté dans cette commune votant traditionnellement pour les radicaux, mobilise ses forces, conseillers municipaux et enseignants. Ils tentent de contrecarrer "l'œuvre de rénovation artisanale et de renaissance paysanne ${ }^{68}$ " mise en place par l'administration de Vichy. Face à eux se dressent l'administration de l'État français, les nouvelles structures corporatistes et même l'Église catholique en la personne du vicaire de la paroisse. En mai 1942, le maire et son adjoint sont suspendus de leurs fonctions. Le Conseil municipal se solidarise avec les deux élus et, dans une motion votée le 16 mai 1942 par la majorité des conseillers,

" [il dit] contester et repousser les griefs qui lui sont faits comme tendancieux et injustifiés [...], affirme que le Conseil municipal est parfaitement homogène et que tous les membres sont solidaires de la gestion et de l'administration des affaires publiques. Atteste qu'il a toujours mené une politique conforme à celle du maréchal Pétain auquel il a voté une motion de confiance le 12 janvier 1942 et la lui renouvelle. Adresse son affectueuse sympathie à M. Lumeau maire avec lequel il se solidarise complètement en le priant de remettre entre les mains du chef du département la démission col-

65. Lettre du président de l'Union des syndicats d'artisans du Morbihan adressée au préfet du Morbihan, datée du 30 mars 1942, Arch. dép. du Morbihan 2W15742.

66. Rapport de l'inspecteur principal de police spéciale Chauchix au service des renseignements généraux du Morbihan et au préfet du Morbihan daté du 7 mai 1942, Arch. dép. du Morbihan 2W15842.

67. Lettre de l'abbé Le Cadre, vicaire de la paroisse de Saint-Jean-la-Poterie, au préfet du Morbihan, non datée, Arch. dép. du Morbihan 2W15742.

68. Rapport de l'inspecteur principal de police spéciale Chauchix au service des renseignements généraux du Morbihan et au préfet du Morbihan daté du 7 mai 1942, Arch. dép. du Morbihan 2W15842. 
lective du Conseil si l'un ou plusieurs de ses membres étaient démissionnés d'office ${ }^{69} "$.

Le 16 septembre 1943, le Conseil municipal est dissout et une Délégation spéciale est nommée avec, à sa tête, Joseph Doucet classé comme républicain de droite. Cette délégation se compose notamment des deux membres du Conseil municipal qui n'avaient pas voté la motion du 16 mai 1942. La parenthèse de droite à la tête de cette municipalité est de courte durée car le 19 août 1944, le CDL du Morbihan rétablit François Lumeau dans ses fonctions. Les ressorts de cette révocation, qui semblaient limpides, montrent que même si tous les notables de gauche du département ne sont pas inquiétés par des procédures de la sorte, ils sont tout de même fragilisés dans leurs positions par l'inversion des rapports de force à l'échelle locale.

Dans la troisième catégorie il nous faut faire une place aux maires de toutes étiquettes politiques qui sont révoqués en raison de leur hostilité, ou tout du moins de leur réticence, à imposer des réquisitions aux agriculteurs de la commune. Les maires révoqués en 1942, 1943 et 1944 le sont majoritairement pour cette raison. Ainsi, le maire conservateur de Néantsur-Yvel dans l'arrondissement de Vannes est suspendu de ses fonctions le 30 mai 1944, pour n'avoir " pas notifié le deuxième contingent d'avoine, il n'a pas veillé à sa réalisation ${ }^{70}$ ". Ces procédures restent malgré tout exceptionnelles, car les conditions d'exercice des mandats municipaux sont si éprouvantes que les candidats ne se bousculent pas pour remplacer les révoqués ou les démissionnaires. En mars 1942, les maires de SaintCaradec-Trégomel, de Le Croisty, de Le Sourn et de Malguénac dans l'arrondissement de Pontivy, sont inquiétés par le préfet du Morbihan pour avoir refusé d'exécuter les ordres de réquisition émis contre les cultivateurs de leurs communes, et pour ne pas s'être libérés des amendes infligées. Le préfet, avant d'entamer des sanctions, recueille l'avis du sous-préfet de Pontivy. Ce dernier lui indique que selon lui,

« il n'est pas souhaitable de remplacer ces maires [...]. Outre les difficultés qui seraient rencontrées pour leur trouver éventuellement des successeurs, l'ouverture de crises municipales serait de nature à engendrer parmi les populations, généralement très attachées à leurs administrateurs locaux, des répercussions fâcheuses qu'il est préférable d'éviter dans les circonstances actuelles ${ }^{71} "$.

Nous sentons bien ici deux phénomènes; tout d'abord l'hésitation des autorités administratives qui craignent de ne pas trouver de successeurs valables et ensuite la crainte qu'elles ont d'entrer en conflit avec la légitimité de ces notables qui s'exprime notamment à travers l'attachement des sociétés villageoises à leurs élus locaux.

69. Motion du Conseil municipal de Saint-Jean-la-Poterie votée le 16 mai 1942 et adressée au préfet du Morbihan, Arch. dép. du Morbihan 2W10584.

70. Arrêté préfectoral du 30 mai 1944, Arch. dép. du Morbihan 2 W11052.

71. Rapport du sous-préfet de Pontivy au préfet du Morbihan daté du 9 mars 1942, Arch. dép. du Morbihan 2W10780. 
En ce qui concerne les démissions, elles sont nettement plus nombreuses, car elles concernent 58,26 \% des maires qui changent sous le gouvernement de Vichy ${ }^{72}$. Les étiquettes politiques des maires qui démissionnent pendant cette période ne nous permettent pas de dire qu'il y a une plus forte démission des élus de gauche. En effet, on comptabilise 24 socialistes ou radicaux soit 35,82 \% des démissionnaires et 31 républicains URD et conservateurs soit $46,26 \%{ }^{73}$. Lorsque l'on compare ce chiffre de 67 démissions avec celui correspondant à la période 1945-1959, où seulement 20 maires démissionnent de leurs fonctions, on peut sans conteste parler d'une crise à la tête des municipalités morbihannaises pendant la Seconde Guerre mondiale.

Les raisons avancées par ces notables pour justifier leur décision sont de plusieurs ordres. Les raisons de santé figurent au premier plan. En effet, la moyenne d'âge ${ }^{74}$ relativement élevée de ces maires explique qu'ils soient plus sujets aux maladies liées au vieillissement. En outre, il faut ajouter que les dernières élections remontent à 1935 et que de nombreux maires qui ont déjà une longue carrière municipale derrière eux commencent à ressentir de la lassitude dans l'exercice de leurs fonctions, lassitude d'autant plus forte que les conditions d'exercice se détériorent nettement pendant l'Occupation.

C'est aussi dans le contexte plus général d'une " opinion qui s'éloigne ${ }^{75}$ " qu'il faut replacer ces démissions. Lorsque l'on étudie leur chronologie (graphique 1) on peut distinguer trois phases. Une première, d'octobre 1940 à décembre 1941, correspond à des démissions en lien avec "l'irritation latente " puis " la vague d'irritation " remarquée par Christian Bougeard chez les paysans des Côtes-du-Nord. La seconde débute en avril $1942^{76}$ pour s'achever vers mars 1943; cette période marquée par le retour au pouvoir de Pierre Laval, se caractérise par une montée en puissance de la collaboration d'état, politique mal perçue par les notables morbihannais, comme par l'opinion publique. La troisième concerne enfin l'année 1944, de janvier à août. On note d'ailleurs une recrudescence des démissions au mois de janvier 1944, cinq démissions, alors que depuis avril 1943 elles se limitaient à une par mois. Les notables, fatigués par presque 10 ans de mandat, lâchent en outre un régime qui se radicalise de plus en plus dans la logique répressive de l'État milicien ${ }^{77}$.

72. Deux autres éléments interviennent pour expliquer les changements à la tête des mairies, $14,78 \%$ de ces maires décèdent et 4,34 \% sont prisonniers, pour $1,73 \%$ des municipalités nous ne possédons aucun élément d'explication.

73. Le reste est composé d'élus sans étiquette, qui n'ont jamais fait de politique ou d'élus dont nous ignorons l'appartenance politique.

74. Par exemple, la moyenne d'âge des maires de l'arrondissement de Vannes était de 49 ans en 1935 et donc de 54 ans en 1940.

75. Pour reprendre le titre d'un chapitre de l'ouvrage tiré de la thèse de Christian Bougeard, Le Choc de la guerre dans les Côtes-du-Nord. 1939-1945, Luçon, Gisserot, 1995, p. 38-39.

76. On peut souligner qu'aux mois de janvier, février et mars 1942 il n'y a aucune démission dans le département.

77. Nous reprenons cette chronologie proposée par Denis Peschanski dans LE BEGUEC, 
Au total, il faut souligner que cette période de la Seconde Guerre mondiale est réellement une rupture dans l'histoire des maires du Morbihan. Une rupture politique à la tête des municipalités qui se manifeste par une nette poussée à droite. Cette rupture s'exprime par l'importance des communes concernées par les changements (37,54\%), changements qui ne relèvent cependant pas d'une politique d'épuration systématique. Il reste à savoir si au-delà, cette rupture politique s'accompagne d'autres évolutions chez les maires du département.

\section{De nouveaux notables sous Vichy?}

Poursuivant l'optique d'une Rénovation nationale, le régime vichyste va tenter de mettre en avant de nouvelles élites locales. C'est l'esprit de l'article 13 de la loi du 16 novembre 1940 qui demande que dans chaque Conseil municipal, il y ait un père de famille nombreuse, un représentant des groupements professionnels de travailleurs et une femme chargée de prendre en main les œuvres d'assistance et de bienfaisance. Mais Vichy ne rompt pas avec le vivier des édiles démocratiquement élus, car 54,78 \% des nouveaux maires entre 1940 et 1944 ont été élus dans un Conseil municipal avant la guerre. Il faut néanmoins nuancer ce chiffre; bien loin d'être un choix délibéré de l'administration pétainiste, il est plus révélateur de la faiblesse du milieu notabiliaire dans beaucoup de communes. Pour les communes rurales principalement, les personnes pourvues de l'instruction, de l'envie et du temps nécessaire pour gérer la mairie sont peu nombreuses. Il n'est donc pas surprenant de les voir occuper déjà des fonctions dans les équipes municipales de l'entre-deux-guerres. L'importance des nouveaux maires n'ayant jamais appartenu à un Conseil municipal (36,52 \%) montre que l'État français tente de promouvoir une nouvelle élite locale.

L'étude comparée des catégories socioprofessionnelles telle que nous la présente le tableau 3 montre que globalement, le régime de Vichy reconduit des notables au profil similaire. On peut noter cependant certaines différences. Tout d'abord, les élites traditionnelles du département, à savoir, les cultivateurs et les propriétaires sont en recul. En ce qui concerne les propriétaires, cette différence est à replacer dans une évolution sur la durée, celle du déclin de l'implication de la noblesse dans la gestion des affaires municipales ${ }^{78}$ et l'accession des exploitants agricoles à la tête des mairies. Le léger recul des agriculteurs est plus difficile à expliquer compte tenu de la volonté du retour à la terre affichée par l'État français. On peut cependant émettre l'hypothèse que les agriculteurs vont se retrouver en concurrence avec d'autres catégories favorisées par ce même régime.

Gilles et Peschanski, Denis (dir.), Les Élites locales dans la tourmente. Du Front populaire aux années cinquante, op. cit., p. 22.

78. Ces résultats sont à mettre en relation avec le recul des conservateurs sous Vichy présenté dans le tableau 1. 
Tableau 3 - Professions des maires nommés sous Vichy et à la Libération

\begin{tabular}{|l|c|c|c|}
\hline & $\begin{array}{c}\text { Maires remplacés } \\
\text { sous Vichy }\end{array}$ & $\begin{array}{c}\text { Maires nommés } \\
\text { sous Vichy }\end{array}$ & $\begin{array}{c}\text { Maires nommés } \\
\text { à la Libération }\end{array}$ \\
\hline Cultivateurs & 39 & 32 & 16 \\
Propriétaires & 14 & 11 & 3 \\
Industriels-Négociants & 8 & 5 & 3 \\
Commerçants & 12 & 9 & 4 \\
Artisans & 4 & 8 & 2 \\
Professions libérales & 10 & 11 & 5 \\
Retraités & 6 & 16 & 3 \\
$\quad$ de la fonction publique & 2 & 6 & - \\
de l'armée & 3 & 6 & - \\
Rentiers & 1 & - & 2 \\
Enseignants & - & - & 18 \\
Autres & 6 & 10 & 56 \\
Inconnus & 10 & 115 & \\
\hline Total & 115 & & \\
\hline
\end{tabular}

Les artisans gagnent ainsi une meilleure représentativité. Ce phénomène participe du même élan doctrinaire visant à célébrer les métiers manuels. Nous avons d'ailleurs montré un exemple de mise en pratique de cette politique dans la commune de Saint-Jean-la-Poterie. Une autre catégorie se voit tout autant sollicitée, c'est celle des retraités, ceux de la fonction publique et de l'armée essentiellement. Un bon exemple est fourni par la ville de Lorient, administrée depuis 1925 par le socialiste SFIO Emmanuel Svob. Il démissionne le 27 janvier 1941, en invoquant la nécessité de mettre " un terme à la vie fiévreuse que, depuis 43 ans, [il a] menée sans lassitude et sans découragement ${ }^{79}$ ". En septembre 1944, le préfet du Morbihan le réinvestit officiellement à la tête de la mairie, il est réélu en 1945 et il décède en 1946. Son remplaçant, le médecin général de Marine en retraite Auguste Donval, est présenté comme "n'ayant jamais fait de politique et ne voulant pas en faire, sauf celle de M. le Maréchal, chef de l'État ${ }^{80}$ ". Le choix de cet officier repose sur un attachement inconditionnel à la politique du maréchal Pétain et également sur le réseau des relations familiales et professionnelles qu'Auguste Donval s'est créé à Lorient. On apprend ainsi que l'un de ses frères est un important négociant de la région, tandis qu'un autre, contre-amiral de réserve a exercé des commandements à la base militaire. Son fils est avocat dans la même ville. Nous nous trouvons là face à un notable au sens politique du terme mais également au sens social. Auguste Donval appartient à tout point de vue à l'élite de la ville. Le 8 mai

79. Lettre au préfet datée du 30 janvier 1941. Une note jointe mentionne le fait qu'il devait être démissionné car il n'est pas français d'origine, Arch. dép. du Morbihan $2 \mathrm{~W} 15743$.

80. Notice de renseignement adressée au préfet du Morbihan datée du 30 janvier 1941, Arch. dép. du Morbihan 2W15743. 
1942, il démissionne cependant, en raison des violentes critiques que lui adresse le Conseil municipal sur la gestion du ravitaillement de la ville. Il est remplacé par Eugène Gallois-Montbrun, administrateur en chef de première classe des services civils de l'Indochine en retraite. Ce colonial est jugé de façon extrêmement favorable par la préfecture, car il a été pendant sa carrière, maire de la ville d'Hanoi. Nous possédons beaucoup moins de renseignements sur ses soutiens lorientais. Cependant sa gestion de la ville va être très critiquée, surtout à partir de janvier 1943, lorsque la ville, durement atteinte par les bombardements, est évacuée ${ }^{81}$. Les services municipaux se réfugient à Sainte-Anne-d'Auray, le maire et ses adjoints ne réapparaissent plus guère à Lorient. La préfecture hésite à le remplacer, car Eugène Gallois-Montbrun a tissé des liens avec le département de Seine-etMarne, département qui aide grandement les réfugiés lorientais. En se faisant l'interlocuteur incontournable de cet échange, il sauve son poste pour quelques mois.

À travers la volonté d'afficher un type de notable bien précis, le régime de Vichy tente de mettre en avant une légitimité politique différente de celle issue du suffrage universel. Cette légitimité est à intégrer à la doctrine conservatrice et élitiste prônée par l'État français ${ }^{82}$. Le 6 octobre 1942, une délégation de sept maires du Morbihan se rend à Vichy afin d'y rencontrer le chef de l'État ainsi que Pierre Laval. Cette sélection est représentative du modèle de notable distingué par Vichy. On y trouve les maires des villes les plus peuplées du département, Eugène Gallois-Montbrun, maire de tendance URD de Lorient, Edmond Gemain, maire de tendance radicale de Vannes nommé en 1941, Léon Jeanpetit, maire de sensibilité de droite d'Hennebont, également nommé par Vichy. Cette ambassade se complète de représentants de la paysannerie, Joseph Guillerme, maire URD de Languidic depuis 1919 et conseiller d'arrondissement (1935-1937) ${ }^{83}$, du maire URD de Guiscriff, Jean Sylvestre élu en 1935, directeur de la Caisse rurale et président des mutuelles agricoles incendies et accidents de la commune. Cette nette coloration paysanne est renforcée par une forte présence de l'Union des syndicats agricoles de la Bretagne méridionale ${ }^{84}$ représentée par René Forest, maire conservateur de Malansac (1923-1947), conseiller général de Rochefort en Terre (1937-1949) et conseiller départemental (1943-1944). Il est membre de la Coopérative des producteurs de blé de la Bretagne méridionale, du Conseil d'administration de trois caisses;

81. Pour des renseignements plus précis sur cet épisode on consultera Gérard LE BouEdEC (dir.), Le Morbihan de la Préhistoire à nos jours, op. cit., p. 374-376.

82. Sur cet aspect on ne peut que renvoyer à la synthèse d'Yves DuRAND, "Les notables ", dans AzEmA, Jean-Pierre et BEDARIDA, François (dir.), Vichy et les Français, op. cit., p. 371-381.

83. Présenté comme « un gros cultivateur très aisé. Très versé dans les questions agricoles " par une fiche de renseignement confidentielle datée de 1943, Arch. dép. du Morbihan 2W11056.

84. L'USABM prend d'ailleurs le contrôle, au sein de la Corporation agricole, de l'ensemble des structures agricoles du département sous le régime de Vichy au détriment des syndicats républicains. 
la Caisse régionale de réassurance de la Bretagne méridionale, la Caisse mutuelle d'assurances sociales de la Bretagne méridionale et la Caisse d'allocations familiales agricoles de la Bretagne méridionale. Pendant la Seconde Guerre mondiale, il participe également à la politique de rénovation agricole, on le retrouve ainsi membre du Groupement interprofessionnel laitier, membre du Groupement de répartition des produits indispensables à l'agriculture et membre de l'Union régionale corporative agricole. Cette délégation comprend également Louis Le Léannec, maire conservateur de Caudan depuis 1925, dont nous avons déjà cité le fort investissement dans les structures du syndicalisme agricole. Sous le régime de Vichy, il est nommé délégué départemental de l'Union régionale corporative agricole et également syndic régional de la Corporation agricole. En février 1941, un arrêté ministériel le désigne membre de la Commission administrative du Morbihan. Il devient par la suite membre du Conseil départemental du Morbihan et conseiller national à Vichy en 1943.

Lorsque l'on analyse la carrière politique des maires nommés sous Vichy, on peut constater que $29,56 \%$ de ces derniers sont révoqués ou démissionnent avant la fin de leur mandat. Il est intéressant de relever ici que parfois, les populations contestent la légitimité de ces notables imposés par Vichy et réaffirment leur soutien aux élus désignés par le suffrage universel. Par exemple, à Séné, dans l'arrondissement de Vannes, Henri Ménard, maire radical élu en 1929, est remplacé sur ordre de la préfecture en mars 1941. L'installation de son successeur, René Fayet se passe mal car, lors de la première séance, 4 conseillers municipaux démissionnent en protestant contre la façon dont les nouvelles nominations ont été faites. L'ensemble du Conseil municipal, à majorité radicale, est en effet remanié au profit d'une très nette majorité de républicains URD. Un article du Nouvelliste de Bretagne ${ }^{85}$ souligne même que des groupes de Synagots se rassemblent pour exprimer leur mécontentement.

Les fonds d'archives du CDL du Morbihan ne nous permettent pas de présenter un état des lieux des maires vichystes qui sont épurés par les Comités locaux de libération (CLL) ou le CDL à la Libération. Mais nous avons cependant pu suivre la carrière d'un certain nombre de ces maires après la Seconde Guerre mondiale : ils sont 33,91 \% à être réélus à la tête de leur municipalité en 1945, 27,82 \% en 1947, 17,39\% en 1953 et $14,78 \%$ en 1959. À la Libération, des légitimités de nature différente entrent en conflit $^{86}$. Traditionnellement, les historiens insistent à juste titre sur le rejet du régime de Vichy et sur le discrédit qui touche les mouvements de droite,

85. Article daté du $1^{\text {er }}$ avril 1941, Arch. dép. du Morbihan 2W15743.

86. Les maires élus au suffrage universel et qui avaient été démis pour des motifs politiques, devaient normalement être rétablis dans leurs fonctions. Dans le cas d'un maire décédé ou démissionnaire, s'il ne pouvait reprendre sa place, le CDL nommait provisoirement un membre du Conseil municipal élu, dans tous les cas, les maires de Vichy devaient céder leur place. Pour plus de précision on se reportera à Fougere, Louis, MACHElon, Jean-Pierre et Monnier, François (dir.), Les Communes et le pouvoir de 1789 à nos jours, op. cit., p. 499. 
plus impliqués dans l'État français. Mais au niveau local, il semble que ce discrédit soit plus limité et que la conjoncture entre en conflit avec d'autres fondements de la légitimité des notables. Pour comprendre ces réélections, il faut incontestablement faire appel à la position sociale et économique du notable dans la société villageoise.

\section{Les maires du Morbihan à la Libération, été 1944 avril-mai 1945}

\section{L'épuration}

L'ordonnance du 21 avril 1944, organisant les pouvoirs publics en France à la Libération, comporte sept articles consacrés aux municipalités. Le principe réaffirmé est le maintien ou la remise en fonction des conseils municipaux élus avant 1939. Les maires et les conseillers municipaux révoqués ou suspendus par Vichy sont donc théoriquement rétablis dans leurs responsabilités. En parallèle, les conseillers municipaux et les maires nommés par le régime de l'État français, ainsi que ceux ayant collaboré avec l'ennemi sont démis de leurs mandats. Cette ordonnance légifère également sur le statut des pouvoirs résistants. Les CDL et les préfets ont le pouvoir de remanier les conseils municipaux, afin d'y faire entrer des résistants et aussi de tenir compte des nouvelles tendances politiques qui auraient pu se manifester pendant la Libération. L'essentiel des changements à la tête des municipalités morbihannaises à la Libération concerne des révocations, elles sont cependant assez limitées, car elles intéressent 17,24 \% des maires morbihannais. Ces révocations représentent $66,17 \%$ des 68 maires qui quittent leurs fonctions. Les démissions (17,64 \%) sont, quant à elles, motivées par le grand âge, la maladie, l'usure liés à près de dix années à la tête de leur commune ${ }^{87}$.

Les révocations sanctionnent des notables qui ont, soit permis l'avènement du régime de Vichy, soit qui l'ont accompagné en prenant des fonctions dans les structures de l'État français. Il faut y ajouter les maires nommés par ce même régime et qui ne peuvent se prévaloir d'aucune légitimité démocratique. À notre connaissance, il n'y a pas d'exemple de collaboration idéologique dans le corpus des maires du Morbihan. Les six notables révoqués pour collaboration sont sanctionnés soit pour des faits d'enrichissement personnel, soit pour des liens personnels trop intimes avec les Allemands, ou encore pour une obéissance servile aux ordres de l'occupant. Ainsi, le maire URD d'Erdeven dans l'arrondissement de Lorient, élu en 1929, est révoqué par le CDL du Morbihan le 9 mars 1945 pour avoir " favorisé l'ennemi en se mettant à la disposition de la Kommandantur et en manquant totalement d'énergie pour défendre les intérêts de la commune $^{88}$ ". Sa soumission aux ordres des Allemands joue en sa défaveur, mais

87. Les sources préfectorales sont lacunaires pour 11 des 68 changements à la tête de communes morbihannaises à la Libération.

88. Liste des maires révoqués ou annulés à la Libération dressée par la préfecture du Morbihan, Arch. dép. du Morbihan 2W10570. 
on lui reproche également d'avoir failli à la mission dévolue aux notables, c'est-à-dire de défendre au mieux les intérêts de leurs administrés.

Généralement, la révocation du maire nommé par Vichy est bien acceptée par la population. Cependant, dans certaines communes, les décisions des autorités résistantes sont contestées. L'exemple le plus remarquable que nous ayons relevé concerne la commune de Caudan dans l'arrondissement de Lorient. Nous avons déjà présenté son maire, Louis Le Léannec, grand notable morbihannais, très impliqué dans le monde rural, et qui, en raison de son action dans les structures vichystes, est révoqué de ses mandats le 15 juin $1945^{89}$. Cette décision qui intervient tard dans la chronologie de l'épuration ${ }^{90}$, suscite une lettre de protestation signée de 893 électeurs de Caudan ${ }^{91}$. Dans cette lettre adressée au préfet du Morbihan, ils rappellent l'estime et la confiance qu'ils placent dans leur maire, estime et confiance motivées par "son activité et sa haute compétence [...], il est le seul qualifié dans notre commune pour défendre nos intérêts, nous aider et nous guider dans le relèvement de nos ruines ${ }^{92}$ ". Aux élections municipales qui suivent, une seule liste, intitulée Municipalité sortante, se présente aux électeurs. Louis Le Léannec est confortablement réélu au premier tour avec 95,32 \% des suffrages exprimés. Le Conseil municipal le désigne maire par 15 voix sur 16 votants. C'est l'exemple du notable dont la légitimité politique supplante le contexte général qui rejette vivement les élus ayant participé à la politique de l'État français.

Loin d'appliquer à la lettre les directives de l'ordonnance du 21 avril 1944, les autorités préfectorales et le CDL vont prendre en compte les évolutions des notables pendant la guerre. Quelques élus vont ainsi être réhabilités par le CDL. Le maire conservateur de Malansac, René Forest, nommé conseiller départemental de Vichy en 1943 puis nommé par ses pairs viceprésident de cette instance, est logiquement révoqué à la Libération. Cependant, le 24 novembre 1944, le CDL le réhabilite, cette décision étant motivée :

" [Par] son attitude digne et bien française, considérant que, dès l'invasion il a facilité le départ des soldats polonais séjournant dans la commune pour leur éviter la captivité. Considérant qu'il a hébergé des patriotes traqués par la Gestapo, qu'il leur a fourni l'argent nécessaire pour rejoindre leur famille. Considérant que dans ses fonctions de maire il n'a eu que des

89. Pour mémoire nous rappelons qu'il est nommé membre de la Commission administrative du Morbihan en 1941, conseiller départemental en 1943, conseiller national également en 1943, délégué départemental de l'Union régionale corporative agricole et syndic régional de la Corporation paysanne

90. L'étude du cas de Caudan a sans doute été retardée en raison de la situation de la commune sur la ligne de front de la poche de Lorient.

91. Sur une population totale en 1946 de 2141 habitants, chiffre extrait du tableau statistique de la commune de Caudan dans Tableaux statistiques de la population des communes du Morbihan, 1806-1975, dressés par l'Institut national de la statistique et des études économiques.

92. Liste des maires révoqués ou annulés à la Libération dressée par la préfecture du Morbihan, Arch. dép. du Morbihan 2W10570. 
rapports indispensables avec les Allemands, évitant le plus possible de se trouver en contact avec eux. Considérant qu'il a donné l'exemple aux cultivateurs de sa commune en vendant toujours ses produits à la taxe ${ }^{93} \ldots$ ".

Cette litanie d'actions nous permet de distinguer le rôle du maire exemplaire sous l'Occupation. Ce maire idéal doit ainsi donner l'exemple, limiter le plus strictement possible ses relations avec les Allemands et dans la mesure du possible, il doit aider la Résistance. On compte ainsi sur les 45 maires révoqués, 5 qui sont réhabilités par le CDL, essentiellement pour l'aide qu'ils ont apportée à la Résistance. Cependant, ce facteur déterminant doit être couplé avec ce que les autorités administratives appellent un comportement digne, c'est-à-dire, peu de relations avec l'occupant et surtout l'absence de profits liés au marché noir.

\section{Les pouvoirs à la Libération}

Les dissensions liées au contexte de la Libération et à la concurrence pouvant naître entre les pouvoirs résistants vont, dans certaines communes, entraîner des heurts entre, d'une part, les maires et le Conseil municipal, et d'autre part entre les CLL, le CDL et parfois les groupes FFI. L'un des axes de réforme des municipalités, souligné par l'ordonnance du 21 avril 1944, consiste à intégrer dans les municipalités les nouvelles forces politiques émergeant à la Libération. Dans le Morbihan, département dominé par la droite, ce sont les forces de gauche qui vont le plus bénéficier de cette politique. Certains notables installés remettent en cause la légitimité des nouvelles élites municipales issues de la Résistance. Il faut également y voir un conflit de génération, qui aggrave parfois les différences politiques. Le dernier trait concerne la manière dont s'effectuent les changements. De nombreux notables remettent moins en cause le fond des décisions des instances résistantes, que la façon dont elles sont connues, et dont elles s'appliquent. Cette importance de la forme, des règles, de la procédure participe sans conteste à une culture des notables ${ }^{94}$.

Les principaux conflits vont opposer les CLL et les municipalités. Plusieurs décisions de CLL sont désavouées par le CDL après étude des faits. Ainsi, à Saint-Gonnery, dans l'arrondissement de Pontivy, Jean Le Clere, maire républicain de gauche, élu en 1935, est dénoncé par le CLL de sa commune pour des comportements assez vagues qui sont cependant qualifiés " d'indignes ${ }^{95}$ ". Le maire révoqué, contestant cette décision, demande l'arrêt d'un jugement plus motivé; après enquête le CDL désa-

93. Avis de réhabilitation de René Forest par le CDL du Morbihan daté du 24 novembre 1944, Arch. dép. du Morbihan 2W10579.

94. Olivier Wieviorka, dans son étude sur les parlementaires français, souligne l'importance de cet aspect de la culture des notables comme facteur explicatif du vote du 10 juillet 1940, WiEvorka, Olivier, Les Orphelins de la République. Destinées des députés et sénateurs français (1940-1945), Paris, Éditions du Seuil, 2001, p. 75 notamment.

95. Rapport du CDL du Morbihan daté du 23 septembre 1944, Arch. dép. du Morbihan 2W10583. 
voue le CLL de la commune, en ces termes, " considérant que les accusations portées par le CLL de Saint-Gonnery contre le maire Le Clere sont dénuées de tout fondement, propose à l'unanimité à $\mathrm{M}$. le préfet la réintégration de M. Le Clere comme maire ${ }^{96} "$.

Un autre acteur, militaire cette fois, intervient au moment de la Libération pour parfois imposer un conseiller municipal de son choix ou pour déposer un édile à ses yeux trop compromis. L'action des FFI est souvent mal vécue par les notables entrant en conflit avec ce pouvoir résistant. À La Chapelle-Caro, commune de l'arrondissement de Vannes, le maire URD, Edmond Malarte, élu en 1935, semble être relevé de son mandat par un conseiller municipal, Louis Buffe, nommé par le commandant Pierre Mozac, officier de la section locale des FFI. Dans une lettre au préfet développant la situation, Edmond Malarte, indique qu'avec l'appui de la préfecture, il reprenait de plein droit la place dont on l'avait illégalement dépossédé $^{97}$. Il faut cependant relever que ces cas semblent rares et que chronologiquement ils sont limités, pour la majorité d'entre eux, au mois d'août et pour quelques-uns seulement au mois de septembre 1944.

\section{Une nouvelle élite résistante à la tête des municipalités morbihannaises?}

À l'instar du questionnement mis en place sur le nouveau type de notable que le régime de Vichy promeut pendant la Seconde Guerre mondiale, on peut s'interroger sur la typologie des élus qui apparaissent à la Libération.

Les 56 nouveaux maires de la Libération ${ }^{98}$ rééquilibrent la physionomie politique des notables municipaux du département, car à 42,85\%, ils appartiennent à un parti de gauche ${ }^{99}$ (tableau 2). Il faut remarquer l'absence des communistes ainsi que la faible proportion des socialistes SFIO. Ces choix

96. Rapport du CDL du Morbihan daté du 20 avril 1945, Arch. dép. du Morbihan 2W10583. On retrouve des désaveux du même ordre dans les communes de Lignol dans l'arrondissement de Vannes, de Quistinic dans l'arrondissement de Lorient où le CDL va jusqu'à remettre en cause l'appartenance résistante des membres du CLL, ainsi qu'à Kerfourn dans l'arrondissement de Pontivy.

97. Lettre d'Edmond Malarte au préfet du Morbihan datée du 21 août 1944, Arch. dép. du Morbihan 2W10576. Cet exemple n'est pas isolé, ainsi dans la commune du Roc-SaintAndré (arrondissement de Vannes) le maire est chassé de la mairie par les FFI locaux. Il proteste devant le CDL qui semble lui donner raison.

98. La différence avec le nombre des maires qui quittent la direction des affaires municipales à la Libération (68) s'explique par la proximité des élections municipales d'avrilmai 1945. Un certain nombre d'entre eux ne sont pas remplacés.

99. On additionne ici les socialistes SFIO, les radicaux et les républicains de gauche. Il faudrait sans doute nuancer ce classement, néanmoins il semble qu'à la Libération, dans le Morbihan, l'espace politique centriste soit très restreint, entre un MRP qui reclasse de très nombreux élus de droite et des républicains de gauche qui abandonnent cette étiquette pour la bannière radicale, notamment, en raison de la réactivation de la césure droite-gauche sur la question scolaire. 
s'expliquent par la volonté affichée des autorités de respecter au mieux les rapports de force existants avant-guerre dans le département. Nous pouvons cependant souligner qu'en proportion, les démocrates chrétiens avec $12,5 \%$ des nominations, se hissent à une place qu'ils n'occupaient pas après les municipales de 1935. Comme dans le cadre français, le Morbihan voit donc un rééquilibrage des élites locales vers le centre et la gauche à la Libération, rééquilibrage qui répond au glissement à droite du corps des notables sous Vichy.

Ces nouveaux maires, comme ceux nommés entre 1940 et 1944, ne sont pas tous des inconnus dans les conseils municipaux. Ainsi, pour 46,42\%, ils ont déjà été élus conseillers municipaux sous la Troisième République, 9 d'entre eux sont d'ailleurs des maires révoqués ou démissionnaires sous Vichy, et qui reprennent, pour un temps, la direction des affaires municipales. Les autorités de la Libération veulent promouvoir une légitimité démocratique et cherchent des maires ayant déjà été reconnus par le suffrage universel. Cependant, 33,92 \% d'entre eux se réclament d'une autre légitimité, celle de la Résistance. À Sarzeau, le maire conservateur, Elie de Langlais, nommé par Vichy en 1941 est ainsi remplacé par le radical-socialiste Guillaume Bouillard, capitaine dans les FFI. À Pontivy, c'est le radicalsocialiste Eugène Frotté qui est révoqué, le commandant FFI Edmond Gousset, également radical-socialiste, le remplace. La proportion des hommes nouveaux issus de la Résistance est relativement faible, mais elle peut s'expliquer par le fait que le Morbihan reste en guerre jusqu'au 10 mai 1945, date de la reddition de la poche de Lorient. Les résistants FFI morbihannais sont, dans leur très grande majorité, affectés aux combats pour la libération de Lorient et la surveillance du front de la Vilaine.

La présentation des professions de ces maires (tableau 3) permet de mettre en évidence les caractéristiques des notables émergeant à la Libération. Globalement, comme dans le cas des élus de Vichy, le profil morbihannais est respecté, ce dernier se caractérisant par une forte représentation du monde rural. Les agriculteurs représentent ici 23,21\% des nommés, et si on y ajoute les propriétaires terriens, nous arrivons pour les représentants des campagnes à un pourcentage de 33,92\%. Les commerçants et les artisans sont moins favorisés que sous Vichy, avec seulement $10,71 \%$ des nouveaux maires. La grande nouveauté réside dans la progression de la représentativité des classes moyennes, professions libérales et membres du corps enseignant, qui totalisent $12,5 \%$ du corpus. Une progression à mettre en lien avec la montée en puissance des forces de gauche, la présence des enseignants étant ici un bon indicateur de ce phénomène. En ce qui concerne le profil socioprofessionnel de ces notables, on ne remarque pas de rupture dans ce corps des maires morbihannais. Dans ce cas précis, c'est la continuité qui l'emporte. Cependant, il nous faut insister sur le glissement à gauche, on devrait même parler de rééquilibrage, des maires nommés à la Libération dans le département. 
Dans la même optique, on peut relever la suite de la carrière politique de ces maires nommés à la Libération; c'est le meilleur moyen de mettre en évidence la force de leur légitimité. Seuls 42,85 \% de ces édiles voient leur position confirmée par le suffrage universel en 1945, ils sont $23,21 \%$ à être réélus en 1947, 19,64 \% en 1953 et 12,5\% en 1959. Ces chiffres sont à comparer avec ceux des réélections des maires nommés par Vichy : en 1945 (33,91 \%), en 1947 (27,82 \%), en 1953 (17,39 \%) et en 1959 (14,78\%). La différence est relativement faible entre les deux. On peut, dans le cadre morbihannais, remarquer que ces élections municipales de 1945 se déroulent sans les FFI, toujours mobilisés sur le front ${ }^{100}$. Une grande partie de l'électorat susceptible de soutenir ces nouveaux maires manque donc à l'appel au moment des élections. En outre, ces candidats qui ne se représentent d'ailleurs pas toujours, doivent également compter avec certains maires vichystes qu'ils remplacent et qui comptent bien reconquérir leur position municipale grâce au suffrage universel.

Par exemple, dans la commune de Cournon, Jean de Gouyon, grand notable conservateur, qui succède à son père à la tête du Conseil municipal, prend des responsabilités dans l'organisation corporatiste agricole mise en place par Vichy. Il est nommé membre délégué de la Corporation paysanne pour la région de Vannes, et membre du Conseil départemental en 1943. Ces prises de fonctions lui valent d'être révoqué de ses mandats par le CDL du Morbihan en 1944. Il est cependant relevé de son inéligibilité par le Conseil interdépartemental de préfecture le 13 août 1945, car son attitude est " demeurée correcte à l'égard de ce dernier [le gouvernement de Vichy], [...], passive même et ses ambitions se sont surtout bornées aux intérêts de la commune et à l'agriculture ${ }^{101}$ ". En 1944, il est remplacé à la tête de la commune par le républicain de gauche Jean Hervé. Ils sont tous deux réélus conseillers municipaux en 1945. Lors de l'élection du maire par le nouveau Conseil municipal, ils se présentent tous les deux. Jean de Gouyon totalise 11 voix sur 12 conseillers contre 1 à Jean Hervé. Nous voyons bien là l'inégalité de l'assise politique de ces deux notables. L'un, Jean de Gouyon, héritier d'une longue lignée d'élus, conseiller général en 1945, conseiller de la République (1948-1953), est très impliqué dans les structures d'encadrement de la société rurale. Il participe en effet aux instances de direction du puissant syndicat agricole de la Bretagne méridionale. Il est membre du Conseil d'administration de la Caisse régionale de réassurance de la Bretagne méridionale, membre du Conseil d'administration de la Caisse mutuelle d'assurances sociales de la Bretagne méridionale, membre du Conseil d'administration de la Caisse d'allocations familiales agricoles de la Bretagne méridionale. Il préside la Coopérative agricole de la Bretagne méridionale, la Coopérative des producteurs de blé

100. Luc Capdevila fait très justement remarquer que ces 12000 ex-FFI représentent environ 11,5\% du corps électoral masculin, dans CAPDEVILA, Luc, Les Bretons au lendemain de l'Occupation. Imaginaire et comportement d'une sortie de guerre 1944-1945, Rennes, PUR, 1999, p. 287.

101. Rapport du Conseil interdépartemental de préfecture daté du 13 août 1945, Arch. dép. du Morbihan 2W10574. 
de la Bretagne méridionale. En 1947, il est élu président du Centre d'action sociale et rurale du Morbihan. L'autre, Jean Hervé, ne peut mettre en avant qu'une légitimité résistante. Dès lors, dans cette commune, les électeurs privilégient celui qui leur semble être le plus qualifié pour défendre leurs intérêts.

Globalement, l'épuration à la Libération reste limitée au niveau local, mais elle est cependant plus ample que celle de Vichy ${ }^{102}$. À partir de l'été 1944, les forces de gauche plus impliquées dans la Résistance, opèrent un retour en force. L'épuration menée par les structures de la Résistance concerne un profil de notable ayant des liens privilégiés avec le régime de l'État français, mais si cet engagement est contrebalancé par une activité résistante ou même une attitude jugée digne, le plus souvent il échappe aux sanctions. Il faut en outre relever les conflits de légitimité qui se font jour en 1945, entre des notables ayant soutenus ou débutés leur carrière sous l'État français, et les nouvelles élites issues de la Résistance. L'étude de leurs carrières politiques montre que, au niveau local, les électeurs n'entérinent pas forcément l'ostracisme qui frappe les édiles de Vichy.

\section{Les maires du Morbihan sous la Quatrième République, 1945-1959}

\section{5-1953, les recompositions politiques liées aux répercussions de la Seconde Guerre mondiale}

Les élections municipales des 29 avril et 13 mai 1945 marquent le retour à la démocratie dans une France encore profondément marquée par la guerre. Dans le Morbihan, les combats se poursuivent jusqu'aux redditions des poches de Lorient (10 mai 1945) et de Saint-Nazaire (11 mai 1945). De nombreuses communes sont toujours occupées (53 au total) et ne peuvent prendre part à ce scrutin. Elles votent seulement en juillet 1945 . Dans le cas de ces communes souvent dévastées, les problèmes d'organisation s'aggravent; une partie des électeurs ne participent pas au scrutin, étant réfugiés dans d'autres départements. Les dates fixées suscitent une polémique, de nombreux électeurs demandent qu'elles soient repoussées afin de permettre aux prisonniers de guerre et aux déportés de rentrer d'Allemagne ${ }^{103}$. Les élections sont maintenues, mais 6 communes ne présentent aucun candidat. Pour l'une d'entre elle, Landaul, dans l'arrondissement de Lorient, les motivations de cette carence nous sont connues. La municipalité expédie en effet un télégramme au sous-préfet qui explique : "Aucun bureau formé - Aucun électeur ne s'est présenté - nous attendons le retour des prisonniers ${ }^{104}$. "Il semble que dans le cas des

102. Pour rappel 21 maires sont révoqués sous Vichy et 45 le sont à la Libération.

103. Sur cette question de l'absence des prisonniers de guerre, des déportés mais aussi des travailleurs en Allemagne, on se reportera à l'article de Jacqueline SAINCLIVIER, " Le retour à la paix dans l'Ouest de 1944 à? ", Annales de Bretagne et des Pays de l'Ouest, $\mathrm{n}^{\circ} 104$, tome 1,1997 , notamment p. 101-102.

104. Rapport du sous-préfet de Lorient au préfet du Morbihan daté du 18 avril 1945, Arch. dép. du Morbihan 2W12809. 
autres communes ${ }^{105}$, l'absence de candidat s'explique par la non-préparation des élections, car les populations pensaient qu'elles seraient reportées. Ainsi, dans l'arrondissement de Pontivy, les maires déclarent au souspréfet qu'il serait "souhaitable que les élections n'aient pas lieu avant le retour des prisonniers, et qu'ils étaient persuadés qu'au dernier moment le Gouvernement retarderait les élections ; c'est ce qui explique que dans presque toutes les communes aucune liste n'a été actuellement dressée ${ }^{106}$ ". Cependant, ces communes élisent toutes un Conseil municipal au second tour de scrutin.

La question du retour des prisonniers et des déportés explique que la campagne politique soit des plus restreinte. Pensant que ces élections n'auraient pas lieu, les partis politiques s'investissent peu dans la propagande. Le sous-préfet de Lorient se fait l'écho de cette situation et il analyse le mécontentement grandissant comme lié au maintien des dates :

" Aucune campagne positive n'est enregistrée jusqu'à ce jour; ni réunions, ni affiches, ni articles. Quelles que soient leurs tendances, les gens expriment leur mécontentement et semblent particulièrement accessibles à l'attitude généralement réservée des prisonniers à l'égard du Gouvernement. Les milieux pétainistes exploitent habilement ce qu'ils appellent "une erreur grossière"; les résistants, qui partagent au fond cette impression, sont désarçonnés et certains accusent le Gouvernement de vouloir les "noyer" dans une opération qui le discrédite ${ }^{107}$."

Cet état d'esprit explique les importants taux d'abstention relevés par le préfet du Morbihan, taux qui culminent parfois à 35 \% dans les campagnes, avec cependant une moyenne de $30 \%$ d'abstentionnistes parmi les inscrits ${ }^{108}$. Ces chiffres divergent de la situation nationale qui est marquée par " une véritable mobilisation du corps électoral ${ }^{109}$ ", l'absence des ex-FFI, des déportés, des prisonniers de guerre, des travailleurs en Allemagne mais aussi des nombreux réfugiés morbihannais, explique en partie ces chiffres de l'abstention. Il faut sans doute y voir aussi l'impact

\footnotetext{
105. La Grée-Saint-Laurent, Baud, Bieuzy, Le Croisty dans l'arrondissement de Pontivy, Landaul dans l'arrondissement de Lorient et Evriguet dans l'arrondissement de Vannes. 106. Rapport du sous-préfet de Pontivy au préfet du Morbihan daté du 16 avril 1945, les élections étant prévues pour le 29 avril, Arch. dép. du Morbihan 2W12809. Un rapport du sous-préfet de Lorient au préfet du Morbihan daté du 18 avril 1945, précise ainsi pour la commune de Landaul " qu'aucun candidat ne s'est présenté, aucune liste n'ayant été constitué par suite de l'indifférence locale mais sans qu'il faille y voir là une manœuvre quelconque, soit en faveur des prisonniers, soit de défiance vis-à-vis du gouvernement ", Arch. dép. du Morbihan 2W12809.

107. Arch. dép. du Morbihan 2W12809, Rapport du sous-préfet de Lorient au préfet du Morbihan daté du 18 avril 1945.

108. Arch. dép. du Morbihan 2W12809, Rapport du préfet du Morbihan au ministre de l'Intérieur daté du 30 avril 1945.

109. L'expression est empruntée à la synthèse de Gilles MoRIN, «Les élections locales de 1945 : la normalisation de la vie politique ", Historiens et géographes, n 357, avril-mai 1997, p. 224 .
} 
d'un quotidien encore très difficile, marqué par les pénuries, qui fait passer les enjeux politiques au second plan.

Les résultats des élections, présentés dans le tableau 1, montrent que les traditions politiques du département persistent alors même que les élections de 1945 représentent, avec 44,06 \% le plus fort taux de renouvellement à la tête des municipalités depuis $1929^{110}$. Le scrutin municipal de 1945 marque donc une rupture certaine, il semble cependant qu'au regard des renouvellements à l'échelle de la Bretagne, le chiffre du Morbihan soit assez faible. Ainsi, pour les Côtes-du-Nord, il atteint le chiffre de 59,3 \% et dans le Finistère-Sud il est de 73,9 \% (arrondissement de Quimper) ${ }^{111}$. Lorsque l'on compare ces chiffres avec ceux d'un autre département au profil politique assez proche, voire encore plus conservateur, comme la Mayenne étudiée par Rémy Foucault, on s'aperçoit que les taux de renouvellement y sont encore plus faibles, $16 \%$ en 1935, 36,5 \% en 1945, $23 \%$ en 1947 et $24,6 \%$ en $1959^{112}$. Le tableau 1 montre que globalement les forces de droite conservent leur position dominante. En effet, la quasi-disparition des conservateurs s'accompagne d'une augmentation sensible du nombre des républicains de l'URD. Ces notables de droite se retrouvent principalement dans les communes rurales et leur localisation (carte 3) montre que la césure est-ouest persiste. Ce maintien des positions de droite dans le département, alors que le contexte politique général leur est défavorable, confirme le décalage des rythmes politiques départementaux ${ }^{113}$. Plusieurs éléments se conjuguent pour expliquer ces résultats. Tout d'abord, ces notables, bien implantés dans leurs communes, ont pour la plupart d'entre eux eu une attitude attentiste voire correcte pendant l'Occupation, et même s'ils ont pu participer à la Rénovation nationale, pour les électeurs, ce péché véniel est vite absout. En outre, incontestablement, on assiste à un renouvellement des générations, de jeunes candidats sans passé politique prennent la relève. Quelques-uns peuvent d'ailleurs se prévaloir d'une action dans la Résistance, comme dans la commune de Landévant, où Louis Cailloce, lieutenant FFI à Cléguer dans le VII bataillon est nommé conseiller municipal par le CDL en 1944, et est élu maire URD de la commune en 1945.

La progression des démocrates chrétiens est également sensible, en 1945, le MRP fait son apparition dans le paysage politique morbihannais. Il séduit 19,23 \% des maires morbihannais. Au niveau départemental, incon-

110. Ce taux était de $18 \%$ en 1929, de $26,44 \%$ en 1935, en 1947 il est de $36,26 \%$, en 1953 de $22,43 \%$, et en 1959 de $25,38 \%$.

111. Ces chiffres sont extraits de la synthèse de Christian BOUGEARD, "Les notables de l'Ouest breton ", dans BOUGEARD, Christian et JARNoux, Philippe (dir.), Élites et notables en Bretagne de l'Ancien Régime à nos jours, Kreiz 10, Brest, CRBC, 1999, p. 253.

112. Chiffres tirés de l'article de Rémy Foucault, « Maires et municipalités de la Mayenne (1935-1953) ", Annales de Bretagne et des Pays de l'Ouest, tome 103, n 3, 1996, p. 65.

113. Même si son cas n'est évidemment pas unique, ainsi dans l'Ouest, la Loire-Inférieure présente également une droite dynamique qui conserve ses positions, voir à ce sujet Gilles RichARD, "La Loire-Inférieure sous la IVe République ", Annales de Bretagne et des Pays de l'Ouest, tome 107, $\mathrm{n}^{\circ}$ 4, 2000, notamment les pages $124 \mathrm{sqq}$. 
testablement, en 1945, la poussée MRP se fait au détriment des terres conservatrices à l'est du département, mais aussi dans les arrondissements de Lorient et de Pontivy ${ }^{114}$. Cette implantation se fait à partir du substrat PDP existant avant 1940. Cependant, lorsqu'on analyse les antécédents politiques de ces maires MRP, on remarque que nombre d'entre eux viennent de la droite conservatrice. Dans l'arrondissement de Vannes, sur les 34 maires qui prennent l'étiquette MRP entre 1945 et 1959, 82,35\% viennent de la droite (conservateurs, républicains URD, indépendants de droite). Ces reclassements se font en 1944-1945, mais également en 1947 et 1953 avec des notables RPF puis républicains nationaux qui rejoignent le MRP. À la Libération, ils profitent de la dynamique MRP et essaient de se refaire une virginité politique en profitant de l'aura résistante du mouvement. Lorsque l'on étudie les 7 nouveaux maires MRP de 1945 dans l'arrondissement de Vannes, c'est-à-dire, ceux qui ne furent jamais élus précédemment, on s'aperçoit qu'un seul conserve l'étiquette MRP en 1947 (ils sont tous réélus) et en 1953 (5 sont réélus). Les autres se partagent entre le RPF (4 maires) et les indépendants (2 maires). Le MRP a donc largement bénéficié du contexte de la Libération en reclassant des élus de droite, mais il ne réussit pas à s'implanter au niveau local. D'ailleurs, l'activité du parti est quasi nulle, un rapport préfectoral daté de novembre 1958 souligne cet état de fait : "Difficile de parler de l'évolution de ce parti car il n'existe pas en tant que tel, puisque le bureau fédéral ne se réunit pratiquement jamais et que les sections n'ont aucune activité ${ }^{115}$. " Le thème qui aura le plus favorisé son implantation dans le département est celui de la défense de l'enseignement libre qui lui permet d'obtenir les faveurs du clergé, force sociale décisive dans le Morbihan ${ }^{116}$. Ce soutien explique qu'en 1947, le MRP résiste bien à la poussée du RPF. Résistance qui s'explique par la mise en place de listes d'union entre les deux mouvements. Un rapport du commissaire des renseignements généraux explique ce maintien :

" [Par] le succès des listes de coalition présentées par le RPF et le MRP auxquels s'étaient joints, dans quelques grosses communes, des éléments radicaux [...]. D'autre part, le Morbihan est un département fortement imprégné dans son ensemble de catholicisme, notamment dans les centres bourgeois comme Vannes, Ploërmel et dans les campagnes, aussi s'explique la

\footnotetext{
114. Ainsi les communes de Guidel, Kervignac, pour l'arrondissement de Lorient et les communes de Meslan, Le Faouët, de Malguénac, pour l'arrondissement de Pontivy, passent de maires conservateurs ou URD à des maires MRP.

115. Rapport de la préfecture du Morbihan à l'occasion des élections cantonales de 1958, Arch. dép. du Morbihan 2W13858.

116. Sur les fondements politiques du MRP on pourra se référer à l'étude de Pierre LETAMANDIA, Le MRP, histoire d'un grand parti français, Paris, Beauchèsne, 1995, p. 49 notamment. Pour le Morbihan, Luc CAPDEVILA qui a étudié ces élections municipales de 1945 rapporte, en citant un rapport du préfet, que « la campagne électorale s'étant crispée sur la question scolaire, les suffrages se sont radicalisés vers la droite ou vers la gauche", dans Les Bretons au lendemain de l'Occupation. Imaginaire et comportement d'une sortie de guerre 1944-1945, op. cit., p. 287.
} 
faveur donnée aux listes de coalition MRP-RPF, qui sont apparues à beaucoup comme des listes "de droite", opposées à des listes communistes $[\ldots]^{117}$."

Dès lors se confirme la coloration nettement droitière du courant MRP, qui s'implante grâce à sa politique de soutien à l'école libre et grâce à son anticommuniste marqué.

Les forces de gauche renforcent leur ancrage politique local en 1945. La mouvance radicale se maintient globalement, la grande nouveauté réside dans l'émergence du parti socialiste SFIO et du parti communiste.

En 1945, le radicalisme conserve ses positions, mais l'évolution du corpus des maires radicaux montre qu'en 1945, ils sont déjà plus dilués dans le département qu'en 1935 où ils occupaient des bastions, notamment au centre et à l'ouest de l'arrondissement de Pontivy (cartes 2 et 3). Nous n'assistons donc pas comme dans le reste du pays à un effondrement du vote radical-socialiste. Cependant, si ce courant reste fort au niveau local ${ }^{118}$, il perd quasiment toute influence sur les scrutins nationaux. À partir de 1945, les radicaux sont peu à peu concurrencés sur leurs terres par des maires SFIO (cartes 4,5 et 6 ).

Les socialistes récupèrent en effet, dans de nombreuses communes, l'électorat radical ${ }^{119}$. À Guéméné-sur-Scorff par exemple, le maire radicalsocialiste Eugène Raude, maire depuis 1919, qui, semble-t-il, ne se représente pas en 1945, voit la Liste républicaine des intérêts communaux (radicaux) battue par une Liste d'union des gauches, groupant des socialistes et des communistes. Le nouveau maire SFIO, Charles Montmayeur, va dominer la vie politique de la commune et du canton jusqu'à la fin des années 1950. La SFIO réussit donc à s'implanter durablement dans les campagnes, en s'appuyant sur une culture politique républicaine et laïque que les radicaux monopolisaient avant guerre. Les socialistes SFIO essaiment également à partir de leur place forte lorientaise. En 1929, ils ne géraient que les communes de Lorient et de Lanester, en 1935, ils y ajoutent la commune limitrophe de Keryado, et en 1945, ils gagnent les communes de Larmor-

117. Rapport du commissaire spécial des renseignements généraux du Morbihan au directeur des renseignements généraux de Paris daté du 20 octobre 1947, Arch. dép. du Morbihan 2W13867.

118. Cet ancrage local est illustré par l'élection d'Alphonse Rio à la présidence du Conseil général d'octobre 1945 à octobre 1946, date à laquelle le MRP Paul Ihuel lui succède. Alphonse Rio fut l'un des grands notables radicaux du département dans l'entre-deuxguerres, élu maire de Quiberon (1919-1929), député (1919-1924 et 1945-1946), sénateur (1924-1940), conseiller général de Quiberon (1945-1949), plusieurs fois membre du gouvernement sous la Troisième République. Il démissionne de son poste de ministre de la Marine Nationale en juin 1940, car il est partisan de la poursuite de la lutte, il vote cependant les pleins pouvoirs au Maréchal Pétain le 10 juillet 1940. Mais les services rendus aux FFI pendant la guerre lui permettent d'être relevé de son inéligibilité en 1944 .

119. En Ille-et-Vilaine, le même phénomène est repéré dès les municipales de 1945, « les élections municipales montrent [...] le maintien de l'équilibre antérieur entre la droite et la gauche mais à l'intérieur de la gauche un glissement s'opère des radicaux-socialistes vers la SFIO et de la SFIO vers le PCF ", dans SAINCLIVIER, Jacqueline, L'Ille-et-Vilaine, 19181958. Vie politique et sociale, Rennes, PUR, 1996, p. 289. 
Carte 4 - Élections municipales de 1947 : étiquettes politiques des maires du Morbihan

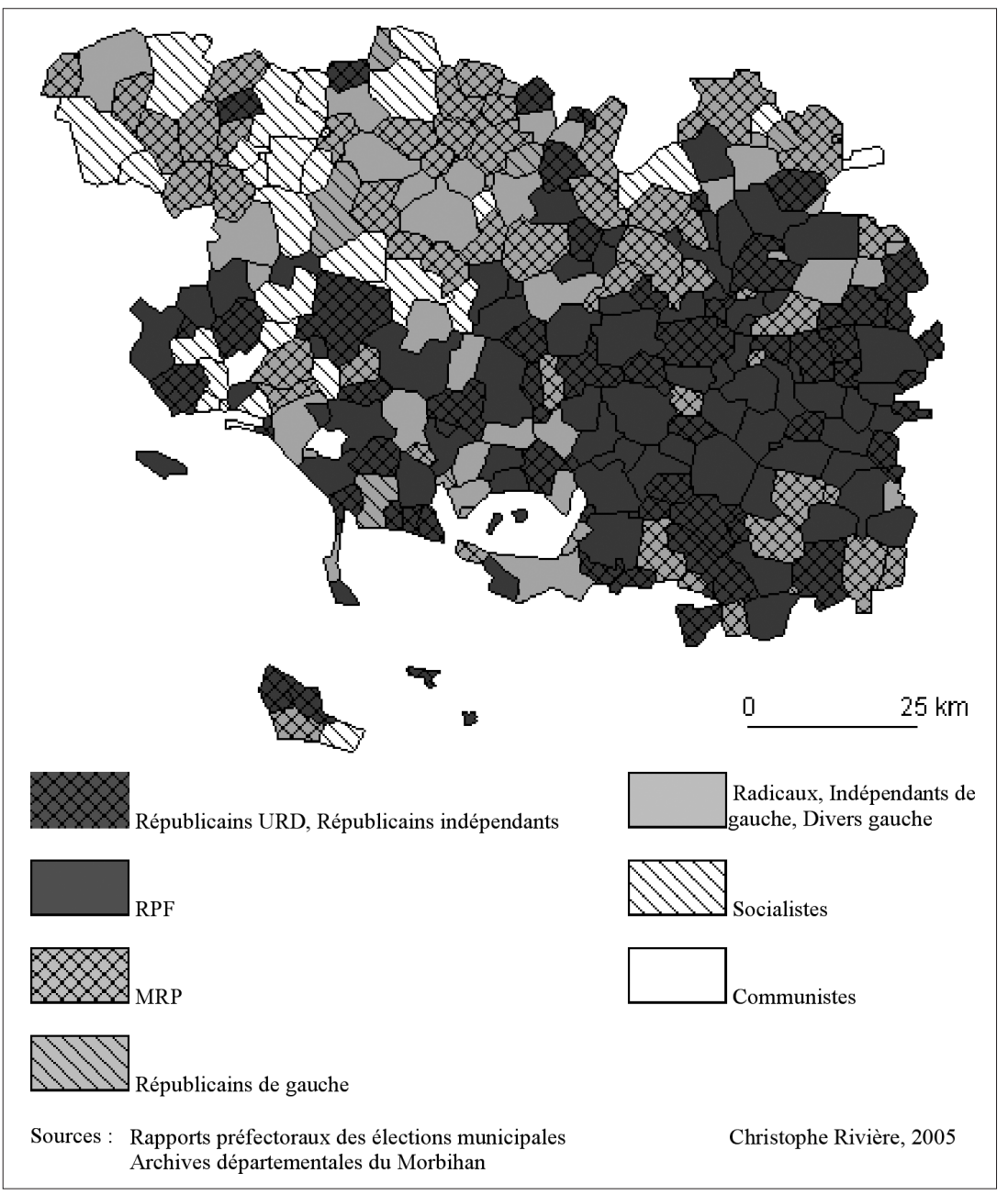

Plage, d'Hennebont et de Nostang. En 1945, leur progression est très nette car ils passent de 4 à 18 élus. En 1947, ils confirment en passant à 27 élus, et en 1953 ils atteignent le chiffre de 29 maires. Les succès de 1945 s'expliquent par le contexte général favorable aux forces de gauche, et par l'engagement résistant de nombreux socialistes. À Auray, Yves Kerroux, nommé maire par le CDL en 1944 et réélu à la tête d'une liste d'union de la Résistance en 1945, est étiqueté socialiste indépendant. Il a servi comme lieutenant dans le II ${ }^{\mathrm{e}}$ bataillon FFI. À Hennebont, le docteur Ferdinand Thomas organise dès 1943 un groupe de sabotage qu'il place sous les 
Carte 5 - Élections municipales de 1953 : étiquettes politiques des maires du Morbihan

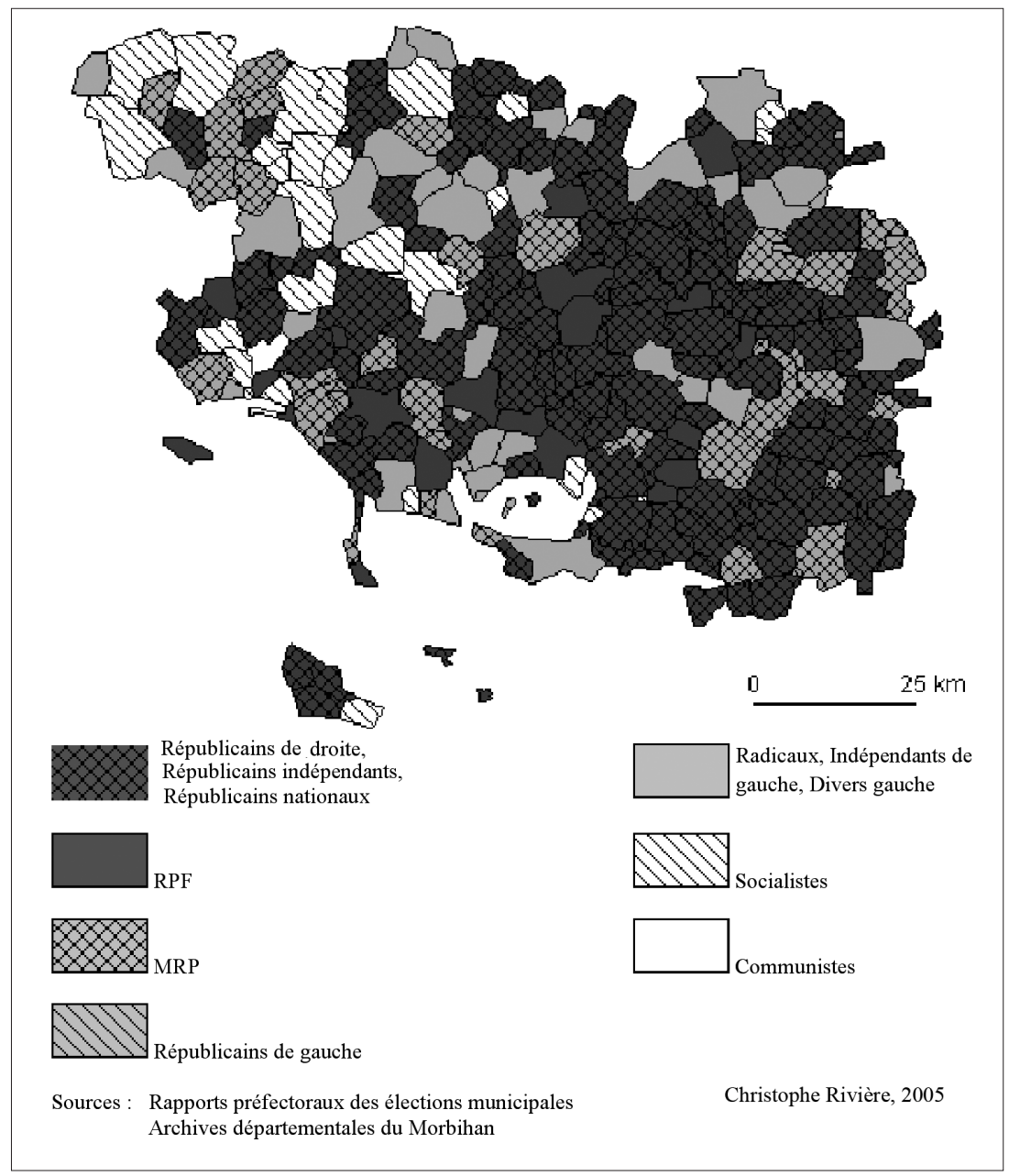

ordres du commandant Muller, chef départemental de l'ORA (Organisation de résistance de l'armée) ${ }^{120}$. Il commande ensuite la Ve compagnie FFI. En 1944, il est également nommé au Conseil municipal par le CDL. En 1945, il est élu maire de la commune et il accède au Conseil général. Mais dans leur bastion lorientais, à partir de 1945, les socialistes sont concurrencés par les communistes qui leurs disputent la prééminence politique.

120. Sur son activité résistante on pourra se reporter à l'ouvrage du Commandant CHAMBERT, Dans le maquis breton avec ceux de l'ORA, Imprimerie Desfossés-Néogravure, Paris, 1946, p. 43. 
Carte 6 - Élections municipales de 1959 : étiquettes politiques des maires du Morbihan

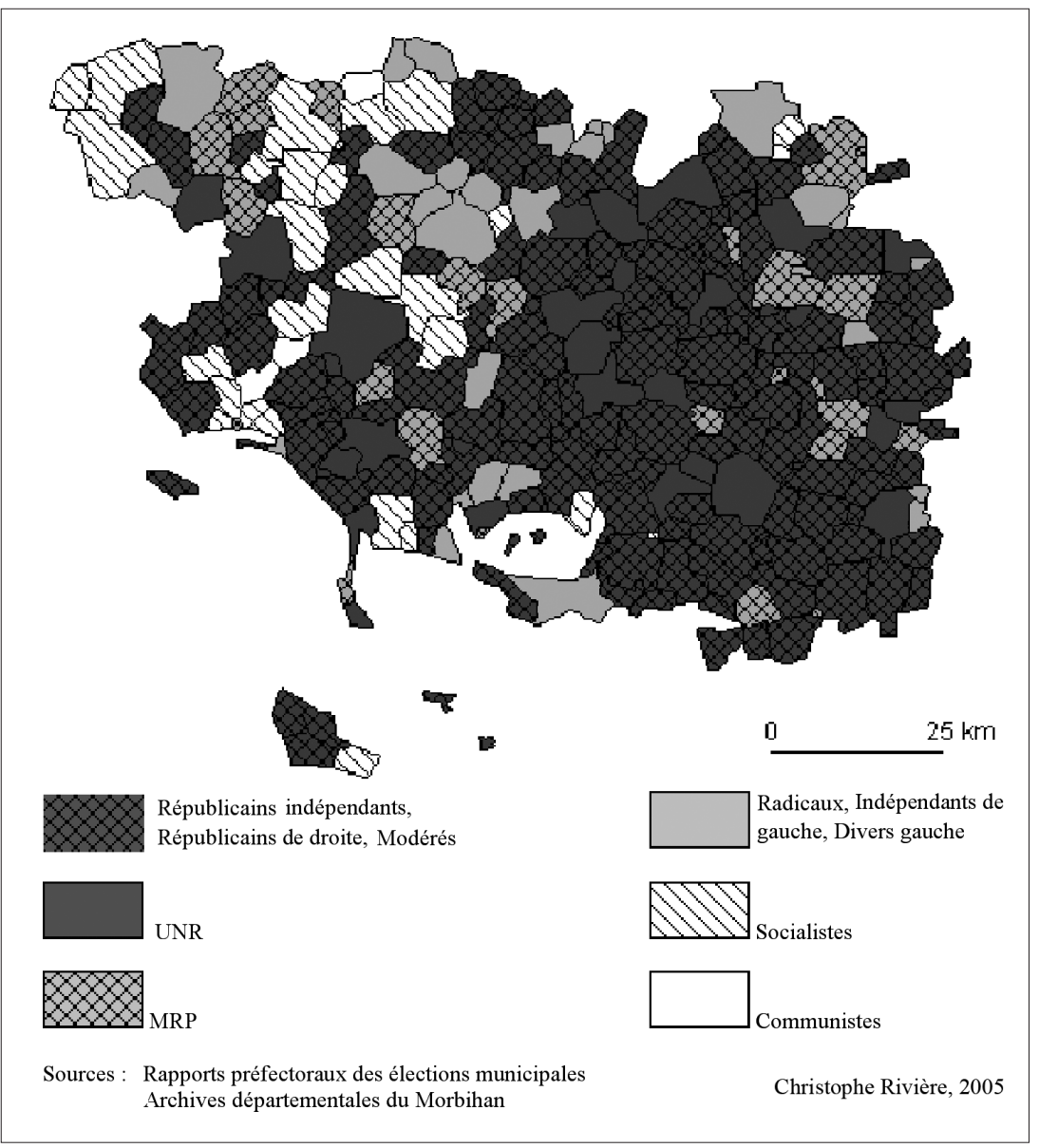

L'implantation communiste reste très faible au niveau local et elle se limite quasiment à la zone lorientaise, le cœur industriel du Morbihan. Le PCF s'appuie sur une forte population ouvrière et sur une légitimité résistante clairement affichée. La commune de Gâvres assure l'élection d'un maire communiste, Henri Padellec, en s'appuyant sur un électorat de marinpêcheurs et d'ouvriers des usines de conserverie. Malgré leurs efforts, les communistes n'arriveront qu'exceptionnellement à s'implanter dans les communes rurales. Concoret, dans l'arrondissement de Vannes, va élire un temps un maire communiste à la tête de son conseil municipal. Cette commune, votant traditionnellement radical-socialiste ou républicain de gauche, appartient à ce que Jean-Jacques Monnier nomme « la diagonale 
gauchisante ${ }^{121}$ ". Le vote communiste s'appuie à Concoret sur la présence d'une nombreuse population de carriers et d'ardoisiers, et également sur l'activité de maquis FTP très populaires dans le secteur de Mauron. Le maire communiste de Concoret, élu en 1945, Victor Berson, est réélu en 1947. Il ne semble pas être un militant extrêmement dynamique dans le parti. Il siège uniquement au Comité départemental de liaison des combattants de la paix et au Comité d'initiative de la conférence paysanne de la paix. Une note d'information des renseignements généraux nous le signale d'ailleurs comme appartenant " depuis longtemps au PCF, son activité au sein du parti est réduite ${ }^{122}$ ». En 1953, il est battu par le républicain national, André Rolland. À Camors, l'élection de Marcel Allanic peut s'expliquer par un tissu dense des réseaux de soutien au Parti. Dans cette petite commune rurale, on relève en effet une section du PCF, un cercle local de l'UJFP (Union des jeunes filles patriotes) et un syndicat CGT (Confédération générale du travail) des ouvriers forestiers ${ }^{123}$. Le PCF doit donc conjuguer la présence d'un fort électorat d'ouvriers ruraux à une activité résistante pour espérer percer dans les campagnes.

La dernière onde de choc, liée aux évolutions politiques engendrées par la Seconde Guerre mondiale, nous semble être la mise en place du RPF. À partir de 1947, ce mouvement va bouleverser le paysage politique morbihannais. Le Rassemblement, s'appuyant sur les principaux chefs départementaux de la Résistance, va en revendiquer l'héritage ${ }^{124}$. La doctrine officielle souhaite transcender la traditionnelle dichotomie droite-gauche et le mouvement tente de recruter des élus de toutes tendances, communistes exceptés. Au regard des chiffres, les maires RPF de 1947 proviennent en majorité de la droite classique. Majoritairement, les cantons conservateurs et URD de l'arrondissement de Vannes : La Gacilly, Rochefort-en-Terre, Questembert, Malestroit, votent RPF. La partie centrale de cet arrondissement rejoint les rangs gaullistes, la persistance du vote par-delà les événements est ici très probante. Les conservateurs, les républicains URD et les indépendants de droite totalisent 34,7 \% des 46 maires RPF de 1947 dans cet arrondissement. Le courant démocrate chrétien semble lui aussi succomber à l'attraction, mais il faut sans doute relativiser ce recrutement centriste, car il peut s'agir de notables de droite qui se sont reclassés au MRP en 1945, et qui reviennent vers une formation plus proche de leurs vues

121. Monnier, Jean-Jacques, Le comportement politique des Bretons, 1945-1994, op. cit., p. $83 s q q$.

122. Arch. dép. du Morbihan 2W13870, Note d'information des renseignements généraux datée du 12 novembre 1952.

123. Arch. dép. du Morbihan 2W13879, Rapport des renseignements généraux au préfet du Morbihan, janvier 1957.

124. Le RPF, qui est créé pour mettre en œuvre les objectifs institutionnels du général de Gaulle, réactive visiblement les anciens réseaux de la Résistance et pour beaucoup d'anciens du gaullisme de guerre, "le Rassemblement [fut une] répétition de la Résistance ", expression de Jérôme POUMEYRoL, "Le RPF dans la mémoire gaulliste ", dans De Gaulle et le RPF 1947-1955, Paris, Armand Colin, 1998, p. 839. 
politiques. Le RPF va aussi attirer des notables radicaux et même certains socialistes $\mathrm{SFIO}^{125}$. Ces maires sont pour la plupart élus dans l'arrondissement de Lorient. Ainsi, Adrien Charrier, gaulliste résistant, maire radicalsocialiste puis RPF de Port-Louis (1934-1959), conseiller d'arrondissement radical-socialiste de Port-Louis (1934-1940), conseiller général RPF puis républicain social puis UNR de Port-Louis (1949-1967), et président du Comité départemental RPF (1947-1948), illustre ce recrutement de centre gauche. La coexistence d'élus de traditions politiques différentes va poser des problèmes au Rassemblement, qui réactive en son sein la division estouest du département, entre des élus de la région lorientaise issus du courant radical-socialiste voire socialiste et des élus de l'arrondissement de Vannes venant de la droite. La crise éclate lors des élections législatives de 1951, en raison du refus RPF de tout apparentement avec les listes MRP et modérée. Les élus gaullistes lorientais soutiennent la liste RPF homogène et nombre d'élus RPF, issus de la droite, quittent le Rassemblement et militent pour la liste d'union ${ }^{126}$. Après l'épisode des législatives de 1951, le Rassemblement est clairement en reflux dans le département.

L'intervalle 1945-1953 est riche de ruptures, les taux de renouvellement sont les plus importants de la période, les enjeux nationaux (poussée à gauche, apparition du MRP, raz de marée RPF en 1947) semblent, au regard des étiquettes, renouveler profondément la vie politique départementale ${ }^{127}$. Mais, la droite résiste et conserve ses positions en 1945, et les nouveaux partis recrutent beaucoup parmi les anciens édiles conservateurs qui se reclassent. Les ondes de choc de la Deuxième Guerre mondiale s'atténuant, les notables de la droite modérée retrouvent leurs positions dominantes. On peut donc parler, pour cette période, plutôt d'une parenthèse caractérisée par des ruptures en surface et des permanences très fortes sur le fond.

\section{3-1959, le retour de “ l'ancien esprit conservateur ${ }^{128}$ »}

À partir de 1953, de nombreux éléments permettent de conclure à une normalisation après les précédents scrutins marqués par le contexte de la Libération. Les forces de gauche voient leur progression nettement ralentir, même si les socialistes SFIO ou les élus classés comme divers gauche, continuent à gagner quelques mairies, le mouvement de conquête est

\footnotetext{
125. Le cas le plus significatif étant celui de Julien Le Pan ancien maire de Lorient (19461951), ancien secrétaire départemental de la SFIO, qui rejoint le RPF le 7 août 1951.

126. Sur ce sujet on pourra se reporter à notre article « Les mouvements gaullistes dans le Morbihan, 1946-1958 ", Bulletin de la Société polymathique du Morbihan, juillet-août 2005, p. 251-304.

127. Gérard GRUNBERG parle pour la période d'effraction de la vie politique nationale au niveau local. Ces enjeux nationaux se retirent après 1953, "Les notables et les partis ", dans Le Beguec, Gilles et Peschanski, Denis (dir.), Les élites locales dans la tourmente. $\mathrm{Du}$ Front populaire aux années cinquante, op. cit., p. 424.

128. Expression du préfet du Morbihan dans un rapport au ministre de l'Intérieur, le 25 janvier 1953, Arch. dép. du Morbihan 2W13870.
} 
moindre que celui de la période $1945-1947^{129}$. Les partis plus structurés comme le MRP et surtout le RPF sont en net recul. Seuls les mouvements de la droite modérée progressent sensiblement.

Une constante qui semble se faire jour réside dans la grande liberté que les notables locaux, et notamment les élus de droite, prennent avec les étiquettes politiques. L'analyse des reclassements politiques déjà abordée par quelques historiens ${ }^{130}$, montre que certains sortants mettent en place des stratégies afin de mieux coller aux changements. La réflexion sur les changements d'étiquette au sein de la droite doit aussi prendre en compte le fait que de nombreuses sources soulignent que les classifications partisanes, d'une façon générale, n'ont pas grand sens dans le contexte local ${ }^{131}$. Il semble d'ailleurs que les étiquettes revendiquées par les élus locaux de droite ne s'accompagnent pas de la mise en place de structures justifiant l'appellation de parti politique ${ }^{132}$. Un rapport du préfet du Morbihan, parlant des modérés, abonde dans ce sens :

" Il ne s'agit pas à proprement parler d'un parti organisé mais de la réunion de tendances appartenant à la droite classique et que rallie leur identité de vue au sujet des problèmes religieux et scolaires lesquels demeurent toujours au premier plan des préoccupations dans le Morbihan ${ }^{133}$. "

En 1953, l'étiquette de républicain national est très en vogue; elle est remplacée en 1959 par celle de modéré. Lorsque l'on compare les mairies tenues par les conservateurs et les républicains de l'URD en 1935 (54,40\%) et celles revendiquées par les modérés en 1953 (50,5 \%) et en 1959 (55,68\%) on ne peut que constater une continuité dans les chiffres. L'analyse cartographique confirme que les modérés de 1953 et de 1959 héritent globalement des positions politiques des conservateurs et des

129. Le phénomène est encore plus net lorsque que l'on regarde le nombre des conseillers municipaux, la SFIO totalise 5,32 \% des conseillers municipaux en 1945, 11,55\% en $1947,9 \%$ en 1953 et $8,53 \%$ en 1959. Le Parti communiste peut compter sur $2,12 \%$ des conseillers municipaux en $1945,4,32 \%$ en $1947,2,02 \%$ en 1953 et $2,2 \%$ en 1959 . Il y a donc incontestablement un recul à partir de 1953.

130. Le lecteur pourra se référer à l'approche d'Éric DuHAMEL, "Les reclassements. Analyse d'un objet ", dans Le Beguec, Gilles et Peschanski, Denis (dir.), Les Élites locales dans la tourmente. Du Front populaire aux années cinquante, op. cit., p. 95 sqq.

131. La persistance dans les municipalités, d'étiquettes politiques n'ayant plus de signification dans le contexte national, comme les républicains de gauche ou la fédération URD en 1947, confirme l'idée d'une temporalité décalée à l'échelle locale.

132. Sauf peut-être pour l'étiquette de paysan, car le 25 avril 1946, une réunion tenue à Vannes fonde le Parti paysan dans le département. Cette réunion, organisée par Yves du Halgouët, voit l'élection d'un comité directeur composé de délégués cantonaux, un embryon d'organisation politique est donc créé. Mais cette tentative de fédérer les électeurs ruraux de droite au sein d'une nouvelle structure échoue, car les notables locaux ne soutiennent pas cette initiative. L'étiquette n'apparaît en effet qu'en 1953 et seulement $3,42 \%$ des maires s'en réclament. Rapport de police adressé au préfet du Morbihan, le 25 avril 1946, Arch. dép. du Morbihan 2W11936.

133. Arch. dép. du Morbihan 2W13870, Rapport du préfet du Morbihan au Ministre de l'Intérieur daté du 25 janvier 1953. 
républicains URD de 1929 (cartes 1, 2, 5 et 6). Ce sont d'ailleurs parfois les mêmes hommes qui restent à la tête de leur mairie, à l'image d'Eugène Denis, élu maire de Lanouée en 1919 dans l'arrondissement de Pontivy. Il est réélu en 1929 sous l'étiquette d'URD, puis en 1935 comme conservateur. En 1945, il se représente comme URD, puis MRP en 1947, républicain national en 1953 et modéré en 1959. Cette propension des notables morbihannais à privilégier, à partir de 1953, des étiquettes politiques qui ne les obligent en rien à entrer dans des structures contraignantes, s'explique par le rejet des partis de masse. Ces partis, comme le RPF, sont très hiérarchisés et les décisions des directions parisiennes doivent être appliquées par les élus locaux. Ce fonctionnement va à l'encontre des traditions des notabilités locales, qui ont l'habitude d'intégrer des structures réactivées uniquement au moment des élections, leur laissant ainsi une plus grande marge de manœuvre.

Ce retour des notables modérés à partir de 1953, va se faire au détriment du MRP, il est fortement concurrencé, comme nous le montrent les cartes 5 et 6, par les républicains nationaux en 1953 et les modérés en 1959. Ce phénomène, très visible dans la partie sud-est de l'arrondissement de Vannes, ne correspond d'ailleurs pas toujours à des changements à la tête des mairies, mais s'explique par les taux importants de reclassement politique des élus. À Billiers par exemple, commune votant démocrate chrétien depuis 1935, Auguste Le Groumellec, est élu maire PDP en 1945 puis MRP en 1947, et en 1953, il apparaît comme républicain national. À Caro, le cas de Pierre Bocandé illustre la sinuosité de certains parcours d'élus de droite. Conseiller municipal depuis 1935, élu sur la liste de Victor d'Aubigny, maire URD depuis 1920, Pierre Bocandé est nommé maire en 1942, il apparaît comme URD en 1945, comme MRP en 1947, puis comme Républicain national en 1953, et comme modéré en 1959. La décrue MRP se confirme aux élections de 1959, seuls $12,12 \%$ des maires se réclament du mouvement contre $14 \%$ en 1953 et $19 \%$ en 1947 et 1945.

Le RPF va souffrir également de ces reclassements. Aux élections du printemps 1953, il ne totalise que 22 (8,36 \%) maires contre 75 en 1947 (28,62\%). La rupture des élections législatives de 1951 permet la mise en place par Raymond Marcellin d'une structure, l'Union pour la défense et le progrès des intérêts morbihannais, qui semble être la seule ayant réussi la réunion des différents courants de la droite morbihannaise. Ce mouvement, fondé en juin 1951, regroupe les tendances de la droite modérée militant pour la liste d'union des modérés et du MRP. L'Union bénéficie du soutien actif des trois sénateurs indépendants ex-RPF, et d'une partie des anciens conseillers généraux RPF. Elle peut compter sur le soutien d'anciens cadres gaullistes. Paul Chenailler, ancien délégué départemental RPF (1947-1949), semble apporter tout son poids de directeur du quotidien La Liberté $d u$ Morbihan pour soutenir l'implantation de Raymond Marcellin ${ }^{134}$. Georges

134. Un rapport de Gilles Mabin, délégué départemental du RPF (1951-1953), avance que "La Liberté du Morbihan est un journal hostile au RPF, je suis persuadé d'ailleurs qu'il est 
Gougaud, également ancien délégué départemental du Rassemblement (1949-1951), est nommé en 1953 secrétaire administratif de l'Union des indépendants. Il semble donc que l'échec du RPF ait facilité la mise en place d'une structure assez lâche permettant à un homme, Raymond Marcellin, d'asseoir localement sa carrière politique ${ }^{135}$.

Le contexte politique de l'année 1958 a des répercussions fortes dans le département, les structures appelant au retour du général de Gaulle au pouvoir, apparues à partir de 1956, se mobilisent. L'activisme des notables modérés semble le plus important. Au sein du comité directeur de l'Association de soutien au général de Gaulle on trouve des modérés comme Louis Le Montagner, président du comité, notable bien implanté ${ }^{136}$, qui débute sa carrière politique en 1944. On relève aussi la présence de Yannick Dubois, maire de Béganne, proche des réseaux Marcellin ${ }^{137}$ et membre du Comité de direction. Mais le mouvement le plus dynamique est le Comité républicain fondé le 28 mai 1958, qui s'appuie sur une mobilisation importante des notables locaux ${ }^{138}$. L'ensemble de ces mouvements s'unifie au sein de l'UNR (Union pour la nouvelle République), fondée à la fin de l'été 1958 et animée par Hervé Laudrin dans le Morbihan. Malgré l'investissement de l'année 1958, l'entrisme des notables modérés est faible au sein de l'UNR. Sans doute le souvenir de l'échec du RPF bloque-t-il les adhésions. Le courant gaulliste remonte cependant aux municipales de 1959 avec 32 élus (12,12\%). Il faudrait affiner l'étude, mais il semble que le renouvellement des hommes soit important et que l'UNR, tout en s'appuyant sur l'héritage RPF, et avec un recrutement qui semble plus marqué à droite, crée une nouvelle dynamique au niveau local. Cependant, la place que l'UNR joue dans la vie politique morbihannaise est sans commune

actuellement entièrement entre les mains de M. Marcellin ". Rapport de Gilles Mabin à la direction du service de presse et d'information du RPF, le 22 juin 1951, Arch. du RPF p. $372-374$.

135. Pour des renseignements plus précis sur l'implantation de ce grand notable morbihannais, on se reportera aux analyses d'Eric ALARY, "Raymond Marcellin : l'exemple d'une implantation locale et le début d'une carrière politique ", dans RICHARD, Gilles et SAINCLIVIER, Jacqueline (dir.), La Recomposition des droites en France à la Libération 19441948, op. cit., p. 313-323 et au travail de Christian COLLOBERT, La Carrière politique : le cas Raymond Marcellin, mémoire de maîtrise d'AES, UHB Rennes, 1984.

136. Son grand-père fut maire de la commune de Merlevenez, lui est maire de Guidel (MRP en 1945, RPF en 1947, républicain national en 1953 et CNI en 1959), conseiller général de Pont-Scorff (1955-1967), député indépendant paysan d'action sociale (1958-1962) et enfin sénateur (1974-1983).

137. Sa carrière, ancrée à droite, débute par sa nomination à la tête de la municipalité de Béganne par le CDL en 1944, il apparaît alors sous l'étiquette d'URD, en 1945 il est élu comme MRP, puis réélu comme RPF en 1947, comme républicain national en 1953 et comme CNI en 1959. Il est candidat aux législatives de 1956 sur la liste d'Union des indépendants et paysans et des républicains nationaux menée par Raymond Marcellin.

138. Ainsi, le 2 juin 1958, 30 des 38 conseillers généraux signent une motion du Comité où ils demandent " respectueusement et fermement à M. le Président de la République française d'appeler sans délais le général de Gaulle pour sauver l'Algérie française, l'unité nationale et la République. " Dans le même communiqué, on apprend que près de 60 maires ont rejoint le Comité. Informations extraites de La Liberté du Morbihan du 2 juin 1958. 
mesure avec ce qu'avait été le RPF entre 1947 et 1951. Le Morbihan est en effet entré dans l'ère du modéré Raymond Marcellin ${ }^{139}$.

Il apparaît donc que les ruptures politiques de la période étudiée, quoique bien réelles, n'entament guère la force des permanences. Dans les années 1930, le corpus des maires du Morbihan réagit peu au contexte national. La Seconde Guerre mondiale se révèle une rupture majeure au regard des changements à la tête des municipalités, mais aussi à travers les rapports de force et les étiquettes politiques affichées. Cependant, une analyse plus précise montre que ces évolutions ne remettent pas en cause le substrat politique du département, de nombreuses adhésions partisanes étant temporaires et les reclassements nombreux. En outre, à partir de 1953, la physionomie politique du département est assez proche de celle des années 1930, la parenthèse de la guerre s'étant refermée. L'analyse politique d'un corpus de notables au travers du seul prisme de l'événementiel, quoique très riche, apparaît cependant limitée pour expliquer la force des permanences. Il faudrait en effet enrichir cette réflexion par une approche prosopographique afin de déterminer la nature de ce qui fait la longévité de certaines carrières. L'apport du para-politique semble en effet essentiel, notamment en ce qui concerne la mise en place de réseaux, qu'ils soient syndicaux, associatifs, professionnels voire familiaux ${ }^{140}$. Sans aucun doute, cette approche montrerait des évolutions plus perceptibles, comme par exemple, dans les campagnes, la prise en main des municipalités par les exploitants agricoles au détriment des propriétaires. Ce sont vraisemblablement ces évolutions structurelles qui permettent aux comportements politiques d'évoluer, beaucoup plus que la seule conjoncture politique.

\footnotetext{
139. Ce dernier est en effet, en plus de ses nombreuses fonctions ministérielles, député du Morbihan (1946-1974 et 1981-1997), conseiller général de Sarzeau (1953-1998), maire de Vannes (1965-1977) et sénateur du Morbihan (1974-1981). Il achève sa conquête du département en mars 1964 en succédant au MRP Paul Ihuel à la présidence du Conseil général. Voir à ce sujet, LE BouEDEc, Gérard (dir.), Le Morbihan de la Préhistoire à nos jours, op. cit., p. 438 sqq.

140. Réflexion déjà engagée par certains historiens notamment par Pascal PLAS, "Élites et édiles : le poids des réseaux ", dans Le Beguec, Gilles et Peschanski, Denis (dir.), Les Élites locales dans la tourmente. Du Front populaire aux années cinquante, op. cit., p. 47-62, et au niveau régional, BOUGEARD, Christian, "Regards sur les réseaux de notables en Bretagne (des années 1930 aux années 1950) ", Annales de Bretagne et des pays de l'Ouest, tome $103, \mathrm{n}^{\circ} 3,1996$, p. $31-51$.
} 


\section{RESUME}

L'étude des maires du Morbihan des années 1930 à la fin des années 1950, période marquée par des ruptures historiques majeures, permet de s'interroger sur la place de l'événement, de la conjoncture, dans la vie politique locale.

La dynamique du Front populaire, les épurations liées à la mise en ouvre de la Rénovation nationale de Vichy puis celles entreprises à la Libération, marquent indiscutablement la période et influent sur les représentations municipales.

Mais si des évolutions peuvent être relevées, c'est cependant la force des permanences, par-delà l'événement, qui caractérise sans doute le mieux le corpus étudié.

\section{ABSTRACT}

The study of the mayors of the departement of Morbihan (Brittany) over the period spanning the 1930s until the late 1950s - a period imbued with major historical landmarks - triggers off a reflection on the impact of historical events on local politics.

The dynamic of the Popular Front, the purges of the National Revolution implemented by the Vichy government followed by the purges of the Liberation unquestionably shaped the era and determined the choice of local councillors.

However, what best characterizes the mayors of Morbihan, notwithstanding a few changes, is their stability. 